\title{
LA RESISTENCIA CON EL CHICLE: LOS MAYAS ENTRE EL CAPITAL CHICLERO Y EL ESTADO MEXICANO EN LA DÉCADA DE 1920
}

\section{Resistance with Gum: The Maya Between the Chewing-gum Capital and the Mexican State in the 1920s}

\author{
Ei Kawakami* \\ doi: https://doi.org/10.31644/ED.V9.N1.2022.A14
}

Resumen: A finales de la década de 1920, casi tres décadas después del fin de la Guerra de Castas de Yucatán (1847-1901), los mayas del Territorio Federal de Quintana Roo seguían prácticamente al margen del gobierno mexicano. No recurrían más a la lucha armada contra las fuerzas gubernamentales, pero tampoco se sometían por completo. Su arma, ahora, era el chicle, producto forestal que abundaba en la zona maya y que se cotizaba altamente en el mercado estadounidense. Algunos jefes mayas gozaban de los privilegios que les daba el gobierno, como el permiso para explotar el chicle en terrenos nacionales o la exención del pago de los derechos de explotación, pero no respetaban todas las reglas que se les imponía — por ejemplo, cobraban "derechos de explotación" a otros explotadores e invadían los campamentos chicleros de los que no querían pagarlos- . Por su parte, la mayoría de los explotadores optaban por obedecerles, porque necesitaban el chicle de la zona gobernada por ellos. El gobierno tampoco los sometía, porque necesitaba su ayuda para mantener la paz en la región y desarrollar la industria chiclera. Este artículo analiza esta relación triangular entre los mayas, el Estado y el capital en Quintana Roo de la década de 1920, enfocándose en una contienda ocurrida entre los mayas, el gobierno mexicano y Miguel Ángel Ramoneda, un inversionista mexicano que tenía concesiones forestales en la zona maya. El objetivo del artículo es demostrar la importancia que como factores político-económicos tenían los mayas en el territorio y dilucidar la estrategia de resistencia de los jefes mayas.

Palabras clave: mayas, chicle, Quintana Roo, Revolución, reforma agraria, Francisco May, José Siurob.

\footnotetext{
* Mtro. en Estudios Regionales, profesor-investigador Universidad Keio, Tokio, Japón. Correo-e: kawak@keio.jp. Fecha de recepción: 21/06/2021. Fecha de aceptación: 09/01/2022. Fecha de publicación: 31/01/2022. (c)) BY-NC-ND
}

EntreDiversidades. Revista de Ciencias Sociales y Humanidades, Vol. 9, Núm. 1 (18), enero-junio 2022. Páginas: 325-359 ISSN-e: 2007-7610. https://doi.org/10.31644/ED.V9.N1.2022.A14 
Abstract: At the end of the 1920s, almost three decades after the end of the Caste War of Yucatán (1847-1901), the Maya of the Federal Territory of Quintana Roo were practically independent from the Mexican government. They were no longer fighting the government with weapons, but were not completely submitted either. Now, its weapon was the chicle, a primary raw material of chewing-gum, abundant in the Mayan area and highly valued in the U.S. market. Some Mayan chiefs received privileges from the government, such as permission to exploit chicle on national lands, or exemption from payment of exploitation fee. But they did not respect all the rules set by the government: for example, they charged "exploitation fee" to other exploiters and invaded chicle camps of those exploiters who did not want to pay them. Most of the exploiters chose to obey them, because they needed the chicle of the area. The government could not take strong measures against those chiefs either, because it needed their help for the stability in the region and the development of the chicle industry. This article analyzes the triangular relationship between the indigenous people, the State, and the capital in the 1920s Quintana Roo, focusing on a conflict that occurred between the Maya, the Mexican government, and Miguel Ángel Ramoneda, a Mexican investor who had forestry concessions in the region. Its objective is to demonstrate the importance of the Maya as political and economic factors in Quintana Roo and to reveal the resistance strategy of their chiefs.

Keywords: Maya, chicle, chewing-gum, Quintana Roo, Mexican Revolution, agrarian reform, Francisco May, José Siurob.

\section{Introducción}

Un día en febrero de 1926, en la primera plana de The New York Times salió un artículo cuyo encabezado decía: "Una ciudad maya enterrada, con seis templos, hallada en Yucatán”. Se trataba de lo que actualmente se llaman las ruinas mayas de Muyil, en el estado de Quintana Roo. Ya se conocían en el extranjero varias ruinas mayas del estado de Yucatán, como las de Chichén Itzá, y había empezado una excavación científica por parte del Instituto Carnegie de Washington, pero la mayor parte del entonces Territorio Federal de Quintana Roo era una tierra desconocida. El artículo decía:

La costa oriental de la península de Yucatán es una de las partes más silvestres y menos conocidas del hemisferio occidental. Hasta hace poco se consideraba peligrosa, salvo para grandes grupos armados, por la hostilidad de los nativos. Hace unos años, sin embargo, se declaró una tregua entre el gobierno mexicano y los indios y ahora los nativos están pacíficamente empleados como recolectores del chicle. ${ }^{1}$

\footnotetext{
${ }^{1}$ Trad. propia: "The east coast of the peninsula of Yucatan is one of the wildest and least-known parts of the Western Hemisphere. Unitl recently it was regarded as unsafe, except for large armed parties, because of the hostility of the natives. A few years ago, however, a truce was declared between the Mexican Government and the Indians and now the natives are peacefully employed as chicle gatherers" (NYT, "Buried Maya City, with Six Temples, Found in Yucatan". 9 de febrero de 1926).
}

EntreDiversidades. Revista de Ciencias Sociales y Humanidades, Vol. 9, Núm. 1 (18), enero-junio 2022. Páginas: 325-359 ISSN-e: 2007-7610. https://doi.org/10.31644/ED.V9.N1.2022.A14 
La expedición dirigida por Herbert J. Spinden, del Museo Peabody de la Universidad de Harvard, pudo realizar el trabajo con el apoyo del "General" Francisco May, "antes considerado como uno de los jefes indios más peligrosos", quien les dijo: "Cooperaré con ustedes al máximo para localizar las reliquias de mis ancestros. [...] Preferimos el actual negocio de chicle a la guerra". ${ }^{2}$

¿Cómo es que un "jefe indio" "antes peligroso" se dedicaba al negocio de chicle? May era heredero de los mayas que protagonizaron la Guerra de Castas de Yucatán (1847-1901). Aún dos décadas después del fin oficial de la rebelión, los mayas se mantenían prácticamente independientes del gobierno mexicano. Los jefes mayas generalmente sostenían relaciones amistosas con el gobierno y aceptaban ciertos proyectos, como la fundación de escuelas rurales o la construcción de vías de comunicación, pero seguían gobernando sus aldeas con sus propias reglas, como la pena de azotes, sin dejar que el gobierno interviniera. Por otro lado, el Territorio de Quintana Roo y el estado de Campeche eran los principales productores, a nivel mundial, del chicle, materia prima de la goma de mascar altamente cotizada en el mercado estadounidense. Los jefes mayas se ponían de acuerdo con los explotadores del chicle, ya sea para cobrarles "derechos de explotación" en la región que gobernaban o para venderles el chicle que ellos mismos producían. Los explotadores, por su parte, tenían que respetarlos si querían continuar con la extracción chiclera. El gobierno también debía pasar por alto varias de las irregularidades que cometían, porque de ellos dependía la estabilidad de la región y el desarrollo de la industria chiclera, que era la principal en la región.

La relación entre los mayas y el chicle es un tema que se menciona bastante pero no se explora con detalle en los estudios existentes. Por un lado, tenemos una vasta historiografía sobre los mayas, pero lo que ha captado la mayor atención de los estudiosos son la Guerra de Castas (Reed, 1964; González, 1970; Lapointe, 1983; Rugeley, 1996, 2009; Dumond, 1997; Sullivan, 1998, 2004; Villalobos, 2006; Dutt, 2017, por mencionar solo los más destacados) y los mayas que se separaron de May a finales de la década de 1920, considerados los herederos de los protagonistas de la misma rebelión (Villa, 1945; Bartolomé y Barabas, 1977; Sullivan, 1989; Hostettler, 1996; Careaga, 1998). Por consiguiente, existe una laguna historiográfica acerca de los mayas de las primeras décadas después de la rebelión, cuando empezaron a participar en la industria chiclera y cuando May fue el jefe más poderoso. ${ }^{3}$ A esta época generalmente se le menciona como un epílogo de la rebelión o como un período en que los mayas dejaron de resistir por participar activamente en el mercado de chicle (Villa, 1945: 30-32; Reed, 1964: 250-256; Bartolomé y Barabas, 1977: 42-51; Ramayo, 2014: 30).

Por otro lado, tenemos una historiografía, menos abundante, sobre el chicle. Mientras existen buenos trabajos enfocados en distintas regiones productoras de chicle, basados principalmente en la historia oral (Schwartz, 1990; Ponce, 1990; Vadillo, 2001), los estudios generalizadores de la historia de la industria tienden a enfatizar la inicua relación entre el productor y el capital extranjero y cuando refieren a los mayas adoptan una interpretación parecida de que la sociedad maya rebelde se debilitó y se fragmentó por participar en la industria chiclera (Konrad, 1987: 501-502; 1991: 159-169; Redclift, 2004: 43-81; Mathews, 2009: 52-59).

\footnotetext{
${ }^{2}$ Trad. propia: "I will cooperate with you to the utmost in locating the relics of my ancestors. [...] We prefer the present chicle business to war" (NYT, "Buried Maya City, with Six Temples, Found in Yucatan". 9 de febrero de 1926).

${ }^{3}$ Existen importantes trabajos pioneros por Ramos (1999, 2001), Villalobos (2004) y Ramayo (2014).
}

EntreDiversidades. Revista de Ciencias Sociales y Humanidades, Vol. 9, Núm. 1 (18), enero-junio 2022. Páginas: 325-359 ISSN-e: 2007-7610. https://doi.org/10.31644/ED.V9.N1.2022.A14 
Si bien es cierto que el chicle les hizo abrirse más al mundo exterior, tales interpretaciones simplistas ignoran varios hechos importantes. Primero, negociar con el mundo exterior el acceso a los recursos forestales empezó desde la época de la Guerra de Castas, cuando los mayas ofrecían a los explotadores de Honduras Británica los derechos de cortar caoba o palo de tinte en su territorio a cambio de la compra de armas. Asimismo, las divisiones y rivalidades entre los jefes también existían durante la rebelión (Dumond, 1997; Sullivan, 1998; Villalobos, 2006).

Además, en cuanto al proceso en el que los mayas se fueron integrando al sistema nacional de México y aquel en el que fueron participando en la industria chiclera e integrándose al sistema mundial capitalista, ambos no se desarrollaron de manera homogénea. Los intentos del gobierno de utilizar a los explotadores chicleros para "pacificar" la zona maya no siempre fueron exitosos. Las querellas por la tierra entre los mayas y los explotadores foráneos eran constantes. Además, también existían explotadores que se aliaban con los mayas para dedicarse a las explotaciones o exportaciones clandestinas. A su vez, la política reconciliadora del gobierno hacia los mayas traía resultados paradójicos: los privilegios que se daban a los jefes mayas para la explotación chiclera podían ayudar a que se acercaran más al gobierno pero también a que tuvieran más influencia en la industria y que se enfrentaran con el mismo. Así, lo relevante es que algunos jefes mayas aprendieron cómo funcionaba esta dinámica y la aprovecharon para seguir su resistencia, convirtiendo al chicle en un arma para ello.

Estos últimos puntos son lo que quiero explorar en este artículo. Para dilucidar la complejidad de la relación entre los mayas, los explotadores del chicle y el gobierno mexicano en la década de 1920, analizo una contienda ocurrida a raíz de unas concesiones que el gobierno otorgó a un inversionista mexicano, Miguel Ángel Ramoneda, para explotar y exportar chicle de la región maya. Mi objetivo es esclarecer, a través del análisis de la contienda, la estrategia de resistencia de los mayas de una época en que ya era difícil continuar con la lucha armada. En la primera sección esbozo la situación socio-económica de la época en Quintana Roo y en las siguientes secciones rastreo la contienda cronológicamente.

\section{Quintana Roo en la década de 1920 El chicle}

El chicle, en un sentido estricto, es un producto derivado del látex del chicozapote (Manilkara zapota), árbol de hoja perenne que crece naturalmente en varios estados de México -Tamaulipas, México, Veracruz, Oaxaca, Chiapas, Tabasco, Campeche, Yucatán y Quintana Roo-, en el Departamento del Petén, Guatemala, en Belice y en la costa atlántica de Nicaragua (Alcorn, 2002: 51). El látex se extrae haciéndole al árbol un corte en forma de letras "y" sobrepuestas hacia arriba. Una vez recolectado se cuece hasta que el nivel de la humedad baje al $33 \%$ o menos. Después, se echa a un molde de madera y, cuando se enfría y coagula, se saca una "marqueta" de chicle de 10-12 kilogramos comerciable como materia prima de la goma base, con la que se hace la goma de mascar, chewing-gum. ${ }^{4}$

${ }^{4}$ NARA, RG 84, UD 570, Vol. 161, File 861.7, Waldo E. Bailey, "Chicle Industry of Yucatan Peninsula" Mérida, 15 de septiembre de 1934, pp. 22-29.

EntreDiversidades. Revista de Ciencias Sociales y Humanidades, Vol. 9, Núm. 1 (18), enero-junio 2022. Páginas: $325-359$ ISSN-e: 2007-7610. https://doi.org/10.31644/ED.V9.N1.2022.A14 
La industria moderna de la goma de mascar nació en Estados Unidos en la década de 1840. En un principio la goma de mascar se hacía con otras resinas como la savia de la picea (spruce), pero en 1859 utilizaron, por primera vez, el chicle, del látex del chicozapote, el cual pronto se convirtió en la principal materia prima de la goma base por su especial calidad (Mathews, 2009: 38-44). Por la época que analizamos, la goma de mascar ya se fabricaba en varios países, pero Estados Unidos, o, más bien, tres compañías estadounidenses, casi monopolizaban la producción mundial de la goma: la William Wrigley Jr. Company, de Chicago (60\%); la Beech-Nut Company (20\%); y la American Chicle Company (15\%). ${ }^{5}$ Las dos últimas, de Nueva York, compraban el chicle a través de una subsidiaria conjunta, Chicle Development Company, que a su vez tenía una subsidiaria en México, que se llamaba Mexican Exploitation Company. ${ }^{6}$

Si bien la industria chiclera en la Península dependía del capital de las tres grandes compañías, estas no intervenían directamente en la producción del chicle, sino que lo conseguían a través de intermediarios. Las explotaciones del chicle se efectuaban tanto en los terrenos privados ocupados por el capital estadounidense o inglés como en los terrenos nacionales. Para las explotaciones en los terrenos nacionales mayores de 5000 hectáreas, el gobierno otorgaba concesiones, generalmente por 10 ańos, y para los terrenos nacionales menores de la misma extensión, permisos precarios anuales (Aguirre, 1925: 29). Las tres grandes compañías no poseían ningún terreno en la Península. 7 Tampoco manejaban concesiones o permisos precarios directamente.

Las grandes compañías tenían sus agentes en la Península: en Mérida, en Campeche, en Ciudad del Carmen, en Cozumel, o en Belice. Los agentes se encargaban de conseguir chicle principalmente a base de contratos. La extracción del látex se efectuaba cuando el árbol tenía suficiente látex por las lluvias — la temporada chiclera oficial era de julio a marzo-. Antes de cada temporada los agentes firmaban contratos con intermediarios, llamados contratistas, fijaban el precio y la cantidad del chicle que les comprarían y les pagaban cierta cantidad de anticipos en forma de vales para que reclutaran chicleros, recolectores del látex, e hicieran todos los preparativos de la explotación. Los contratistas, quienes manejaban las concesiones y los permisos precarios, a su vez, pagaban anticipos a los chicleros en forma de provisiones o en efectivo. Los chicleros generalmente eran trabajadores de temporada, quienes pasaban ocho o nueve meses en el bosque trabajando y luego regresaban a su lugar de origen. Durante varias décadas la gran mayoría de los chicleros llegaban de Tuxpan, Veracruz, donde empezó la producción chiclera antes que en la Península, pero poco a poco los peninsulares también fueron aprendiendo a

\footnotetext{
${ }^{5}$ TNA, CO 123/346/3, J. H. Magowan, "Memorandum on the Chewing Gum Industry in the United States of America and Notes on the Manufacturing Process”, Washington, D.C., 26 de agosto de 1932.

${ }^{6}$ NARA, RG 84, UD 570, Vol. 161, File 861.7, Waldo E. Bailey, "Chicle Industry of Yucatan Peninsula" Mérida, 15 de septiembre de 1934, p. 87.

${ }^{7}$ Mexican Exploitation Company sí tuvo en la década de 1910 unos terrenos nacionales rentados en el estado de Campeche y en el Territorio de Quintana Roo para explotar chicle. En ese entonces, cerca de 1000000 hectáreas de la tierra campechana estaban ocupadas por otras compañías estadounidenses y unas 744850 hectáreas del norte de Quintana Roo por el Banco de Londres y México bajo el nombre de colonia Santa María. Véanse NARA, UD 570, Vol. 52, File 800, "Report Regarding Americans in the State of Campeche, Mexico, Consular District of Progreso on August 20, 1913 (brought up to date of September 12, 1913)"; Aguirre (1925: 25-26).
}

EntreDiversidades. Revista de Ciencias Sociales y Humanidades, Vol. 9, Núm. 1 (18), enero-junio 2022. Páginas: $325-359$ ISSN-e: 2007-7610. https://doi.org/10.31644/ED.V9.N1.2022.A14 
“chiclear". ${ }^{8}$ A Quintana Roo se decía que llegaban más de 2000 chicleros cada temporada, de Campeche, de Yucatán, de Tabasco o de Veracruz. Entre los contratistas y los chicleros podían existir dos o tres sub-contratistas más, razón por la que los chicleros ganaban mucho menos de lo que valía el chicle en los puntos de exportación. A finales de los ańos veinte se decía que un quintal (equivalente a 46 kilogramos) de chicle valía 98 dólares estadounidenses en Nueva York y los agentes en los puertos de la Península pagaban 43 dólares por la misma cantidad de chicle, mientras los chicleros recibían solamente 15 o 18 dólares. $^{9}$

A pesar de ello, también es cierto que en la industria chiclera los productores disfrutaban cierta independencia. Las descripciones contemporáneas sobre los chicleros como "hombres libres" o "aventureros" tienen algo de veracidad (Beteta, 1937: 39). El mismo sistema de contratistas que les quitaba una buena parte de la ganancia a los chicleros, les garantizaba cierta autonomía. Y, precisamente, fue el mismo sistema el que permitió a los mayas participar en la explotación del chicle. Ya para la década de 1910 los mayas de Quintana Roo producían el chicle por sí mismos. El chicle producido por los mayas generalmente llegaba a los puertos a través de los comerciantes que se lo compraban en pequeñas cantidades. ${ }^{10}$ Pero algunos jefes mayas, como Francisco May, llegaron a manejar permisos precarios, reclutar chicleros y producir chicle en grandes cantidades. Así fue como pudieron utilizar el producto forestal como un arma para defenderse.

\section{Los mayas}

La Guerra de Castas terminó en 1901, cuando las fuerzas federales ocuparon Santa Cruz, la capital de las fuerzas mayas rebeldes, y al siguiente año el gobierno federal creó el Territorio Federal de Quintana Roo en el territorio que ocupaban los rebeldes. Pero los mayas se dispersaron en el bosque y siguieron una guerra de guerrillas por una década más. Con la llegada del gobierno revolucionario en 1911 empezó la reconciliación de algunos jefes mayas con el gobierno, y tras años de negociaciones, en 1915 el gobierno les devolvió Santa Cruz, que se había convertido en la capital del Territorio. Las opiniones de los jefes se dividieron sobre si tomaban esta oferta o no, y de los grupos que la aceptaron surgió Francisco May como un líder joven (Kawakami, 2013: 1162-1166).

Según el informe de la comisión de estudio que recorrió el Territorio en 1925, los mayas estaban divididos en tres grupos. En el noroeste del Territorio, unas 1500 personas de poblados como Chumpón y Tulum formaban el primero. El que dirigía este grupo era Juan Bautista Vega, originario de Cozumel, pero que siendo niño había caído prisionero en el territorio maya y después de haber crecido entre los mayas lo habían nombrado secretario del general. En el centro del Territorio, Francisco May dirigía el grupo más numeroso de 2500 personas, con su centro en Santa Cruz. En Icaiché, en el sur, por los límites con Campeche y con Guatemala, vivían unas

\footnotetext{
${ }^{8}$ NARA, RG 84, UD 570, Vol. 161, File 861.7, Waldo E. Bailey, "Chicle Industry of Yucatan Peninsula" Mérida, 15 de septiembre de 1934, pp. 19-21; 50-61; 88-89.

${ }^{9}$ AGN, DGG, exp. 2.310(32)5, José Siurob, Payo Obispo, al secretario de Agricultura y Fomento, 4 de noviembre de 1928.

${ }^{10}$ NARA, RG 84, UD 570, Vol. 134, File 850, Rufus H. Lane, Jr., “Quarterly Review of Commerce and Industries", Progreso, 4 de noviembre de 1929.
}

EntreDiversidades. Revista de Ciencias Sociales y Humanidades, Vol. 9, Núm. 1 (18), enero-junio 2022. Páginas: 325-359 ISSN-e: 2007-7610. https://doi.org/10.31644/ED.V9.N1.2022.A14 
treinta familias bajo el mando de Juan de la Cruz Ce. Aunque todos los grupos estaban sujetos al gobierno federal, conservaban su autonomía administrativa, cuya autoridad la asumía el jefe de cada grupo (Aguirre, 1925: 8-14).

Esas regiones prácticamente gobernadas por los mayas eran ricas en chicozapote. En 1912, cuando la Beech Nut Packing Company pidió al consulado estadounidense en Progreso el pronóstico de la cosecha del chicle de la temporada de 1912-1913, uno de los contratistas en Mérida contestó que habría una reducción en la exportación, porque la mayor parte del bosque ya estaba explotada, pero que podría mejorar la situación "si llegara por ejemplo á [sic] ser un hecho la pacificación de los mayas en el territorio" de Quintana Roo. ${ }^{11}$ Para los explotadores del chicle también era importante que mejoraran las relaciones entre los mayas y el gobierno.

Para conseguir chicle en la región maya, los explotadores necesitaban no solo el permiso oficial del gobierno, sino también el de los mayas. Al menos desde 1901 el jefe de los mayas de Icaiché daba "licencia" a los explotadores de chicle de Honduras Británica. ${ }^{12}$ Los de Santa Cruz y los de Chumpón habrían iniciado un poco más tarde a tener contacto con los explotadores del chicle. Konrad indica que los de Chumpón comenzaron desde 1913 (1991: 160). El nombre de May empezó a aparecer en los documentos oficiales y en los periódicos de Mérida en 1916 y ya para ese entonces daba "permiso" a los "trabajadores" en su territorio. ${ }^{13}$

Por falta de pago de estos "permisos" o "derechos" de explotación, los explotadores varias veces tenían que soportar que los mayas asaltaran sus campamentos chicleros. El gobierno lo sabía y a veces incautaba el chicle que se suponía que era robado por los mayas, pero tampoco podía someterlos, ya que no quería que las relaciones con ellos empeoraran. En general, los explotadores preferían negociar con ellos, porque era menos complicado y perjudicial que pelear.

Además de cobrar los "derechos" a los explotadores que buscaban el chicle en las regiones bajo su dominio, May y Vega se convirtieron en contratistas también; es decir, firmaban contratos con los agentes de las compañías estadounidenses u otros contratistas, manejaban permisos precarios, reclutaban chicleros y se dedicaban a la explotación del chicle. Según un informe de la Secretaría de Agricultura y Fomento en 1925, May contrataba unos 150 chicleros a través de 10 sub-contratistas y además compraba chicle a los mayas que explotaban independientemente. ${ }^{14}$ De tal manera que la región maya se ofrecía como un buen campo de trabajo a los peninsulares (Ávila, 1993: 23-25).

Los jefes mayas recibían privilegios del gobierno para emprender sus negocios. Desde 1916, cuando el gobierno empezó a darles permisos de explotación, les eximían del pago de los derechos de explotación y los demás establecidos, los cuales pagaban los compradores del chicle. ${ }^{15}$ May

\footnotetext{
${ }^{11}$ NARA, RG 84, UD 570, Vol. 50, File 861.7, Ángel Rivas, Mérida, a la Cámara Agrícola de Yucatán, 12 de octubre de 1912 .

${ }^{12}$ CO 123/240, No. 97, D. Wilson, Governor of British Honduras, Belize, a J. Chamberlain, 31 de mayo de 1902.

${ }^{13}$ AGEY, PE, caja 527, año 1916, sección Gobernación, Francisco May, Noh Cah Santa Cruz, a Salvador Alvarado, 20 de julio de 1916.

${ }^{14}$ NARA, RG 84, UD 570, Vol. 107, File 320, Informe de la Secretaría de Agricultura y Fomento, México, s/f [septiembre de 1925].

${ }^{15}$ AGN, OC, exp. 241-G-Q-8, Subsecretario de Agricultura y Fomento, México, al presidente de la República, 29 de octubre de 1927.
}

EntreDiversidades. Revista de Ciencias Sociales y Humanidades, Vol. 9, Núm. 1 (18), enero-junio 2022. Páginas: 325-359 ISSN-e: 2007-7610. https://doi.org/10.31644/ED.V9.N1.2022.A14 

capital chiclero y el Estado mexicano...

tenía una ventaja aún mayor: se le tenía otorgado el derecho de utilizar la vía ferroviaria, que unía Santa Cruz de Bravo con Vigía Chico, el puerto más cercano en la costa caribeña. ${ }^{16}$ Sin embargo, a finales de la década de 1920 llegó una amenaza para esos privilegios: las concesiones de Ramoneda.

\section{Mapa 1. Península de Yucatán en la década de 1920}

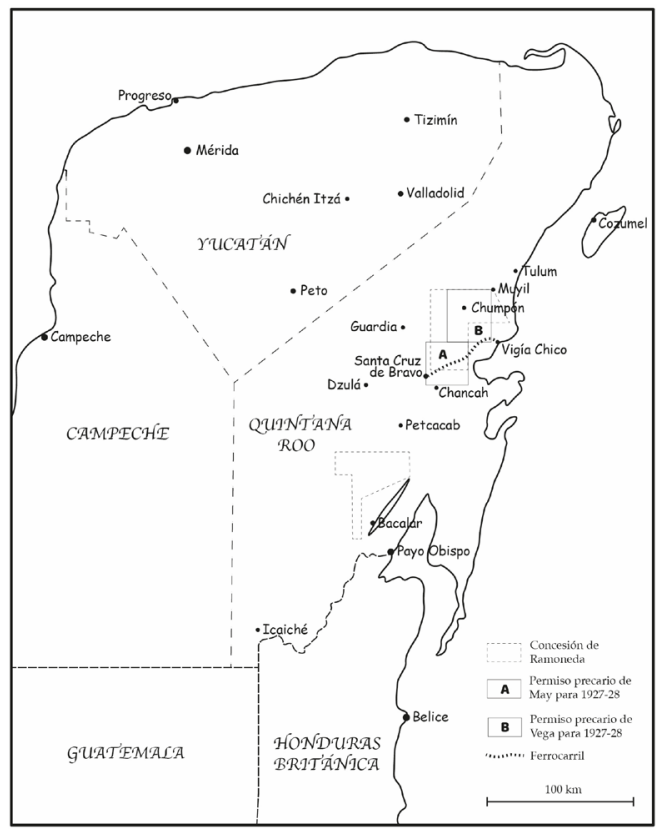

Fuente: AGN, DGG, exp. 2.310(32)10, tomo 2.

"Plano del Territorio de Quintana Roo", septiembre de 1927.

\section{La temporada chiclera de 1927-1928 \\ Las concesiones de Ramoneda}

En marzo de 1926, Miguel Ángel Ramoneda, un joven inversionista mexicano, apenas con 24 o 25 años de edad, ${ }^{17}$ solicitó a la Secretaría de Comunicaciones y Obras Públicas una concesión para reconstruir y explotar el ferrocarril de Santa Cruz de Bravo a Vigía Chico. ${ }^{18}$ Como el ferrocarril fue obra de la ocupación militar del Territorio en el Porfiriato y todavía pertenecía a la Secretaría de Guerra y Marina, la concesión le fue otorgada por esta secretaría en febrero de 1927. Las

\footnotetext{
${ }^{16}$ May comentó, en una ocasión, que Salvador Alvarado, gobernador de Yucatán entre 1915 y 1918, le había entregado la vía con la autorización de Venustiano Carranza. Los historiadores coinciden en que Carranza se la otorgó cuando May lo visitó en la Ciudad de México en 1919. Véanse SBCHBT, AFM, núm. 79-I, Francisco May, México, a Joaquín Amaro, 7 de agosto de 1929; Reed (1964: 252); González (1970: 278).

${ }^{17}$ AGN, EPG, caja 13, exp. 478, Copia de contrato celebrado entre Miguel A. Ramoneda y Mauro C. Angulo, Cozumel, 23 de octubre de 1928.

${ }^{18}$ AGN, SCOP, exp. 501:170-1, Miguel A. Ramoneda, México, al secretario de Comunicaciones y Obras Públicas, 6 de marzo de 1926.
}

EntreDiversidades. Revista de Ciencias Sociales y Humanidades, Vol. 9, Núm. 1 (18), enero-junio 2022. Páginas: 325-359 ISSN-e: 2007-7610. https://doi.org/10.31644/ED.V9.N1.2022.A14 
condiciones eran extraordinarias: a cambio de reconstruir la vía dentro de 7 años y cubrir los gastos de la inspección (50 pesos mensuales) y del sostenimiento del destacamento en Vigía Chico (5 000 pesos anuales), le otorgaron la autorización de utilizarlo por 50 años.

Lo más extraordinario fue el artículo número 18 del contrato, que decía: "La concesión que la Secretaría de Agricultura y Fomento otorgue al Concesionario, se considerará subsidiaria de este contrato y por lo tanto quedará sujeta a los derechos y obligaciones que éste señala". ${ }^{19}$ Ramoneda solicitó, desde el principio, "como subvención o ayuda para poder llevar a cabo", la obra de reconstrucción, el permiso de utilizar unos terrenos nacionales pero "libres de derechos de arrendamiento y explotación”. El joven inversionista consiguió lo que quería. Un mes después de la concesión del ferrocarril, la Secretaría de Agricultura y Fomento le otorgó otra concesión para explotar recursos forestales por 19 años en dos terrenos nacionales: uno de 70000 hectáreas, cerca de la laguna de Bacalar; y otro de 180000 hectáreas, al norte de Santa Cruz de Bravo (véase Mapa 1). ${ }^{20}$

Esta concesión también fue insólita. Desde 1918, cuando se reformaron los sistemas anteriores a la Revolución, ${ }^{21}$ nunca se había concedido un terreno mayor de 100000 hectáreas para las explotaciones forestales en Quintana Roo, y la duración de las concesiones normalmente había sido de 10 años. $^{22}$ Además, Ramoneda no tenía que pagar ni los derechos de explotación del bosque -80 pesos anuales por cada 1000 hectáreas_-, ni los de aprovechamiento de los productos forestales — 50 pesos por cada tonelada de chicle_-, como tampoco el depósito de 32 pesos por cada 1000 hectáreas que a otros concesionarios se les imponían. ${ }^{23}$ Lo único que tenía que pagar eran los derechos de exportación, que, por costumbre, los cubrían los compradores en los puertos. ${ }^{24}$

¿Cómo habrá podido conseguir la concesión con unas condiciones tan insólitas? Ramoneda tenía un hermano, José Ramoneda, quien había sido jefe de la Sección de Bosques Nacionales de la Secretaría de Agricultura y Fomento, la institución encargada de otorgar concesiones forestales. Entre agosto de 1924 y enero de 1925, los hermanos Ramoneda aprovecharon su puesto para conseguir, a través de tres personas "prestanombres", tres concesiones para explotar unos terrenos nacionales, que sumaban 250000 hectáreas, en el sur del Territorio de Quintana Roo.

\footnotetext{
${ }^{19}$ AGN, SCOP, exp. 501:170-1, Copia del contrato celebrado entre Miguel A. Ramoneda y Joaquín Amaro, secretario de Guerra y Marina, México, 1 de febrero de 1927.

${ }^{20}$ DOF, "Concesión otorgada al seńor Miguel A. Ramoneda para la explotación de maderas, gomas y resinas en el Territorio de Quintana Roo", 1 de abril de 1927, pp. 6-7.

${ }^{21}$ AHUNAM, AAA, caja IV, exp. 15, Ejemplar enviado a Amado Aguirre del informe preparado por Juan de D. Rodríguez para el presidente de la República, Payo Obispo, 20 de mayo de 1927.

${ }^{22}$ Véanse los contratos de concesión publicados en el Diario Oficial entre 1918 y 1927.

${ }^{23}$ Véanse, por ejemplo, las concesiones otorgadas a Miguel Conzález y a Manuel Carrillo, en enero de 1925. DOF, “Contrato celebrado con el señor Miguel González para la explotación de maderas, gomas y resinas en terrenos nacionales del Territorio de Quintana Roo"; "Contrato celebrado con el señor Manuel Carrillo para la explotación de maderas, gomas y resinas en terrenos nacionales del Territorio de Quintana Roo”, 13 de marzo de 1925.

${ }^{24}$ AHUNAM, AAA, caja IV, exp. 15, Ejemplar enviado a Amado Aguirre del informe preparado por Juan de D. Rodríguez para el presidente de la República, Payo Obispo, 20 de mayo de 1927.
}

EntreDiversidades. Revista de Ciencias Sociales y Humanidades, Vol. 9, Núm. 1 (18), enero-junio 2022. Páginas: 325-359 ISSN-e: 2007-7610. https://doi.org/10.31644/ED.V9.N1.2022.A14 
Miguel Ángel, que estaba en ese entonces en Nueva York, se contactó con la William Wrigley Jr. Company y logró vender las concesiones a Robert S. Turton, agente de la compañía en Belice.

Aún así, el proyecto de los siguientes años parece que no fue una obra exclusiva de los hermanos Ramoneda. Según un informe confidencial de otro ex-jefe de la Sección de Bosques Nacionales, la concesión forestal de marzo de 1927 era de una cuantía que no podría conseguir "un simple particular" como Ramoneda y con él estaban asociados altos personajes del gobierno: el general Pedro J. Almada; el general Miguel Piña, subsecretario de Guerra y Marina; y el ingeniero Luis L. León, secretario de Agricultura y Fomento, todos muy allegados al presidente Plutarco Elías Calles. ${ }^{25}$ Es difícil comprobar que estas personas estaban detrás del proyecto de Ramoneda, pero sería más lógico considerar que había colaboradores del proyecto en las dos Secretarías que le dieron concesiones extraordinarias. Además, varios acontecimientos que analizaremos más adelante insinúan que algunos, si no es que todos, de estos funcionarios estaban involucrados.

\section{Las oposiciones de los mayas}

Los terrenos que la Secretaría de Agricultura y Fomento concedió a Ramoneda para explotar chicle incluían los terrenos ocupados por Francisco May y por Juan Bautista Vega. El ferrocarril que le concedió la Secretaría de Guerra y Marina para reconstruir y explotar era el mismo ferrocarril que el gobierno había autorizado a utilizar a May años atrás. Así que las oposiciones de los jefes mayas eran de esperarse.

La concesión del ferrocarril salió publicada en el Diario Oficial del gobierno federal el 17 de marzo, y la concesión forestal, el 1 de abril. Pronto, el 11 de abril, May viajó a Cozumel para enviarle un telegrama al presidente Calles. Quejándose de la concesión del ferrocarril, suplicó que reconsiderara sus condiciones para que él lo pudiera seguir utilizando en el transporte de chicle y de víveres. Alegó que desde que se lo entregaron en 1915 lo había venido reparando y ese ańo había gastado 10000 pesos en esas obras. ${ }^{26}$ Seis días después, Vega también escribió al presidente, quejándose de la concesión forestal de Ramoneda. ${ }^{27}$

A pesar de los problemas que causaban las concesiones, los jefes mayas continuaron con sus negocios de chicle. A principios de junio, ambos, May y Vega, consiguieron de la agencia general de la Secretaría de Agricultura y Fomento, en Payo Obispo, permisos precarios para la temporada chiclera de 1927-1928. ${ }^{28}$ May había firmado, una semana antes, en Cozumel, un contrato de compra y venta de chicle con un contratista yucateco, Alfredo Cámara Vales. A juzgar por el tenor del contrato, May tuvo trato con él en la temporada anterior también. Para esta temporada, recibió 50000 pesos de anticipo para la producción del chicle y otros 50000

\footnotetext{
${ }^{25}$ AHUNAM, AAA, caja IV, exp. 15, Wm. Wrigley Jr. Company a M. Ramoneda, 26 de marzo de 1925; M. A. Ramoneda, México, a Wm. Wrigley Jr. Compamy, 19 de febrero de 1927; Ejemplar enviado a Amado Aguirre del informe preparado por Juan de D. Rodríguez para el presidente de la República, Payo Obispo, 20 de mayo de 1927.

${ }^{26}$ AGN, SCOP, exp. 501:170-1, Plutarco Elías Calles, México, a Ramón Ross, 18 de abril de 1927.

${ }^{27}$ AGN, OC, exp. 121-A-M-37, Subsecretario de Agricultura y Fomento, México, a Plutarco Elías Calles, 24 de mayo de 1927.

${ }^{28}$ AHSCJN, serie Amparo en Revisión, exp. 4040, año 1929, Alfonso González Gallardo, México, a Miguel A. Ramoneda, 16 de enero de 1929.
}

EntreDiversidades. Revista de Ciencias Sociales y Humanidades, Vol. 9, Núm. 1 (18), enero-junio 2022. Páginas: 325-359 ISSN-e: 2007-7610. https://doi.org/10.31644/ED.V9.N1.2022.A14 
pesos para comprar chicle a otros productores. Se comprometió a venderle en Vigía Chico todo el chicle que produjera y consiguiera a 80 pesos el quintal, y a comprarle todas las mercancías que necesitara para el consumo de la temporada. Parece que Ramoneda todavía no se había apoderado del ferrocarril, ya que May y Cámara Vales acordaron que este le pagaría 800 pesos mensuales por el flete del chicle de Santa Cruz de Bravo a Vigía Chico y que también pondría una cuadrilla de 10 hombres para reparar la línea ferroviaria. ${ }^{29}$

Siendo cuñado de José María Pino Suárez, Cámara Vales había gobernado Quintana Roo en el ocaso del maderismo, entre noviembre de 1912 y febrero de $1913 .{ }^{30}$ Desde ese entonces se le acusaba de traficar armas y mercancías de Honduras Británica. ${ }^{31}$ Ahora que el gobernador del Territorio era otro yucateco, Antonio Ancona Albertos, disfrutaba de su amparo para seguir con el mismo comercio clandestino e incluso para tener a su disposición un balandro del gobierno para el transporte del chicle. Compraba el chicle a May en Vigía Chico y luego lo enviaba a Cozumel en el balandro y lo vendía a Mac y Compañía, que representaba a Robert S. Turton, agente de la William Wrigley, Jr. Company en Honduras Británica. ${ }^{32}$

May también aprovechaba la "garantía" que daba el gobierno de Ancona Albertos. En agosto de 1927 una partida de mayas invadió los terrenos concedidos a Delio Alonso, Tranquilino Arriaga y Antonio Baduy, a quienes les exigían entre 800 y 1000 pesos por concepto de ocupación del terreno. Luego expulsaron a los chicleros de los campamentos de otro permisionario, Pascual Coral. El agente auxiliar de la Secretaría de Agricultura y Fomento, acompañado de un coronel de la fuerza federal, fue a entrevistar a May, quien "los recibió en forma altanera manifestándoles que no [permitía] que nadie se [metiera] a molestar a sus pueblos ni a trabajar en tierras que le [pertenecían] y que él era el único responsable de sus actos y que a nadie le tenía que rendir cuentas". ${ }^{33}$

Ramoneda también tuvo que contemporizar con May. A principios de noviembre, parece que lo entrevistó y le mostró un oficio de la Secretaría de Guerra y Marina donde se le ordenaba al jefe de Operaciones Militares en Quintana Roo proporcionarle escolta para recibir el ferrocarril. May no estaba de acuerdo y enseguida acudió a Cozumel a enviarle un telegrama al presidente Calles del siguiente tono: "suplícole atentamente informarme si este asunto no lo resolvió Usted favorablemente para mi Tribu". ${ }^{34}$ Estando ahí, recibió un telegrama del jefe de operaciones militares, en el que le avisaba que un teniente coronel iba a acompañar a Ramoneda a recibir

\footnotetext{
${ }^{29}$ SBCHBT, AFM, núm. 14, Contrato celebrado entre Francisco May y Alfredo Cámara Vales, Cozumel, 25 de mayo de 1927.

${ }^{30}$ AGN, PR, caja 34, exp. 19, Acta de nombramiento de Alfredo Cámara Vales como Jefe Político interino del Territorio de Quintana Roo, México, 5 de noviembre de 1912; caja 35, exp. 68, Acuerdo del secretario de Gobernación, México, 28 de febrero de 1913.

${ }^{31}$ AGN, PR, caja 34, exp. 19, Alfonso Carrera Carbó, Santa Cruz de Bravo, al subsecretario de Gobernación, 16 de mayo de 1913.

${ }^{32}$ AGN, DGG, exp. 2.310(32).3, Juan de Dios Rodríguez, México, al presidente de la República, 6 de julio de 1927; Eduardo Gómez Gallardo, México, al secretario de Gobernación, 26 de septiembre de 1927.

${ }^{33}$ AGN, OC, exp. 241-G-Q-8, Subsecretario de Agricultura y Fomento, México, al presidente de la República, 29 de octubre de 1927.

${ }^{34}$ AGN, OC, exp. 121-A-M-37, Francisco May, Cozumel, a Plutarco Elías Calles, 10 de noviembre de 1927.
}

EntreDiversidades. Revista de Ciencias Sociales y Humanidades, Vol. 9, Núm. 1 (18), enero-junio 2022. Páginas: 325-359 ISSN-e: 2007-7610. https://doi.org/10.31644/ED.V9.N1.2022.A14 
el ferrocarril. Entonces, volvió a escribir al presidente diciendo que acataría las órdenes, pero suplicando que reconsiderara el asunto. En diciembre llega Ramoneda a Santa Cruz de Bravo, acompańado del teniente coronel, May le entrega el ferrocarril pero le pregunta si lo puede seguir usando para sacar sus productos con sus propios tractores. Ramoneda se lo niega y le exige 10000 pesos por usarlo por el resto de la temporada chiclera. May no quiere aceptar pero Ramoneda trata de impedir la salida de los productos y la introducción de las mercancías. Al final May propone pagarle 4000 pesos, y, después de tantas vacilaciones, Ramoneda acepta. ${ }^{35}$

\section{El apoyo del gobierno a los mayas}

Las quejas de May sirvieron de alguna manera. Como era de costumbre, el presidente Calles, o su secretario, transcribió los dos telegramas a las autoridades correspondientes: el primero a la Secretaría de Agricultura y Fomento, aunque se trataba de la concesión de la de Guerra y Marina; y el segundo al gobierno del Territorio de Quintana Roo. En ausencia del gobernador, el secretario general del gobierno del Territorio siguió las instrucciones del presidente y entrevistó personalmente a May en Vigía Chico para tomar nota de la negociación con Ramoneda. ${ }^{36}$ Si bien Ramoneda contaba con el respaldo de altos funcionarios del gobierno federal, May también tenía sus propios canales para hacer oír sus súplicas y quejas.

Los permisos precarios que consiguieron May y Vega antes de que empezara la temporada 1927-1928 también fueron frutos de varias quejas y súplicas. Como vimos anteriormente, Vega también había escrito al presidente el 17 de abril, quejándose de la concesión forestal de Ramoneda. Un mes después recibió una respuesta de la Secretaría de Agricultura y Fomento en la que se le prometía concederles "una extensión razonable de terrenos" para explotar productos forestales. ${ }^{37}$ Y la promesa se cumplió. El 2 de junio la agencia general de la Secretaría en Payo Obispo concedió a May y a Vega permisos precarios para explotar, cada uno, 100000 kilogramos de chicle en una superficie de 100000 hectáreas de terrenos nacionales que comprendían parte de la concesión de Ramoneda, por lo que negó la autorización para explotar 200000 kilogramos de chicle que había solicitado este concesionario. ${ }^{38}$ Los terrenos concedidos a May y a Vega ocupaban la mayor parte de la parte norte de los terrenos concedidos en concesión a Ramoneda (véase el Mapa 1). Eran excepcionalmente grandes, ya que los permisos precarios normalmente se

\footnotetext{
${ }^{35}$ SBCHBT, AFM, núm.16, Alfredo Martínez, Payo Obispo, a Francisco May, 15 de noviembre de 1927; núm.15, Francisco May, Cozumel, a Plutarco Elías Calles, s/f [noviembre de 1927]; núm.18, Miguel A. Ramoneda, Santa Cruz, a Francisco May, 8 de diciembre de 1927; núm.17, Acta de la reunión entre Julio A. Surdez, Francisco May, et al., Vigía Chico, 17 de diciembre de 1927; AHSDN, XI/III/3-2456, tomo 1, f.24v., Recibo de Miguel A. Ramoneda, Santa Cruz, 8 de diciembre de 1927.

${ }^{36}$ AGN, OC, exp.121-A-M-37, Plutarco Elías Calles, México a José G. Parres, 12 de noviembre de 1927; Julio Surdez, Payo Obispo, a Plutarco Elías Calles, 5 de diciembre de 1927.

${ }^{37}$ AGN, OC, exp. 121-A-M-37, Subsecretario de Agricultura y Fomento, México, a Plutarco Elías Calles, 24 de mayo de 1927.

${ }^{38}$ AHSCJN, serie Queja, exp. 30, año 1928, Luis G. Rivera, Payo Obispo, a Miguel A. Ramoneda, 1 de junio de 1927; serie Amparo en Revisión, exp. 4040, año 1929, Alfonso González Gallardo, México, a Miguel A. Ramoneda, 16 de enero de 1929.
}

EntreDiversidades. Revista de Ciencias Sociales y Humanidades, Vol. 9, Núm. 1 (18), enero-junio 2022. Páginas: 325-359 ISSN-e: 2007-7610. https://doi.org/10.31644/ED.V9.N1.2022.A14 
daban para explotaciones en terrenos más pequeños de 5000 hectáreas. En resumen, el presidente y la Secretaría optaron por favorecer más a los mayas que a Ramoneda.

\section{Los juicios de amparo de Ramoneda}

Tras conocer los hechos anteriores, nos preguntamos, ¿por qué concedería el secretario León los permisos precarios a los jefes mayas si estaba involucrado en el proyecto de Ramoneda? La verdad es que desde mayo de 1927 León había salido de la Secretaría, dejando el cargo al subsecretario José G. Parres (Dulles, 1961: 380). Sabiendo o no del “complot” de León con Ramoneda, este doctor zapatista no hizo nada para proteger las concesiones de Ramoneda. Al contrario, además de haber dado instrucciones para otorgar permisos precarios a los mayas en los terrenos concedidos a Ramoneda, ordenó que se preparara la declaración de la caducidad de la concesión, lo que se consumó con el acuerdo presidencial del 28 de julio. ${ }^{39}$

Enseguida, el 15 de agosto, Ramoneda presentó una demanda de amparo al juez segundo supernumerario de distrito en el Distrito Federal (D. F.), Juan A. Coronado, contra actos del subsecretario, alegando que aunque efectivamente Parres le envió un oficio señalando el plazo improrrogable de 10 días para defender sus intereses ante la Secretaría, para que no se declarara caduca su concesión, este le había llegado después de cumplirse el plazo. El 20 de agosto el juez le negó el amparo y Ramoneda presentó otra demanda de amparo, con fecha 31 de agosto, ahora al juez primero supernumerario de distrito en el D.F., Julio López Masse, contra actos del presidente de la República y del subsecretario de Agricultura y Fomento, por haber declarado caduca la concesión.

Parece que este asunto causó alguna polémica incluso dentro de la Suprema Corte de Justicia de la Nación. El 6 de septiembre, el juez López también le negó el amparo a Ramoneda. Un mes después, el 3 de octubre, antes de que se emitiera el fallo de ninguno de los dos juicios en la Suprema Corte, el Pleno de la misma resolvió, por unanimidad de 11 votos, que solamente el juez Coronado, quien previno, era competente para conocer de las dos demandas de amparo promovidas por Ramoneda, porque este "en sus dos demandas, reclamó esencialmente el mismo hecho". ${ }^{40}$ Lo extraño es que el 3 de noviembre el mismo Pleno de la Suprema Corte revocó la sentencia dictada por el juez López, del 6 de septiembre, y le concedió amparo a Ramoneda, argumentando que en los dos juicios de amparo "se reclama, en cada uno de ellos, actos distintos" y que "de ejecutarse el acuerdo que declaró la caducidad, se causarían daños de difícil reparación a la parte agraviada". ${ }^{41}$ A diferencia de la resolución anterior, esta pasó apenas por mayoría de seis votos contra cuatro. Una semana después de esto, el Pleno de la Suprema Corte resolvió, ahora sí, por unanimidad de 9 votos, que se confirmaba la sentencia dictada por el juez Coronado, del

\footnotetext{
${ }^{39}$ AGN, OC, exp. 121-A-M-37, José G. Parres, México, a Fernando Torreblanca, s/f [julio de 1927]; AHSCJN, serie Conflicto Competencial, exp. 374, año 1927, Julio López Masse, México, al Secretario de Acuerdos de la Suprema Corte de Justicia de la Nación, 12 de septiembre de 1927. Ese acuerdo presidencial no parece haberse publicado en el Diario Oficial.

${ }^{40}$ AHSCJN, serie Conflicto Competencial, exp. 374, ańo 1927, Resolución dictada en el Pleno de la Suprema Corte de Justicia de la Nación, México, 3 de octubre de 1927.

${ }^{41}$ AHSCJN, serie Queja, exp. 30, ańo 1928, Copia de expedientes relativos a los juicios de amparo núm. 319/927 y 292/27, México, 21 de febrero de 1928.
}

EntreDiversidades. Revista de Ciencias Sociales y Humanidades, Vol. 9, Núm. 1 (18), enero-junio 2022. Páginas: 325-359 ISSN-e: 2007-7610. https://doi.org/10.31644/ED.V9.N1.2022.A14 
20 de agosto, que negó la suspensión de los actos reclamados por Ramoneda, es decir, los actos del subsecretario de Agricultura y Fomento de haberle señalado el plazo improrrogable de 10 días para defender sus intereses. ${ }^{42}$

La existencia de tres fallos contradictorios dio lugar a que la querella se volviera más complicada. En enero de 1928 José Ramoneda, en representación de su hermano Miguel Ángel, pidió al juez Coronado resolver que se librara oficio de requerimiento a la Secretaría de Agricultura y Fomento para que Francisco May, Juan Bautista Vega y otros que estaban dentro de los límites de la concesión de su hermano dejaran de trabajar en la concesión y que los frutos que se encontraban en los límites de la concesión fueran puestos a disposición del concesionario. El juez pidió a la Secretaría un "informe sobre la queja del interesado por incumplimiento de la suspensión decretada”, citando erróneamente el número del primer juicio de amparo en el que se le negó la suspensión. El subsecretario Parres contestó al juez, manifestando que la queja de Ramoneda era improcedente, porque el fallo pronunciado por el mismo juez había negado la suspensión de los actos reclamados por Ramoneda y no fue revocado ni reformado por la Suprema Corte en la ejecutoria del 10 de noviembre. ${ }^{43}$ Sin embargo, después de que José Ramoneda volvió a quejarse del "[e]ncargado accidentalmente" de la Secretaría, el juez resolvió que su queja estaba fundada y que se comunicara esta resolución al presidente de la República para que ordenara al subsecretario cumplir con la suspensión. ${ }^{44}$

Entonces, Parres presentó una queja contra el juez Coronado ante la Suprema Corte con fecha 3 de febrero. Manifestó que el juez le pidió un informe sobre el juicio de amparo en que se negó la suspensión, y alegó que aunque se había concedido la suspensión en otro juicio de amparo anterior, esta no era válida, porque existían dos resoluciones contradictorias sobre un mismo acto reclamado y la última, la que negó la suspensión, debería dejar sin efectos a la primera. Además, como el juez exigía que le devolvieran a Ramoneda la posesión de los terrenos concedidos en concesión, Parres arguyó también que Ramoneda nunca había tenido posesión de los mismos, y adjuntó dos oficios del agente general de la Secretaría en Payo Obispo donde se comprobaba que la Secretaría había otorgado a los jefes mayas permisos precarios para explotar recursos forestales en una gran parte de los mismos terrenos y que el resto de los terrenos tampoco lo ocupaba Ramoneda. ${ }^{45}$

Poco después de que se presentó esta queja, el juez Coronado se declaró incompetente para seguir conociendo el juicio de amparo, "porque el acto reclamado en este amparo se [estaba] ejecutando en el Territorio de Quintana Roo". ${ }^{46}$ Sin embargo, el juez de distrito en Quintana

\footnotetext{
${ }_{42}$ AHSCJN, serie Amparo, exp. 3297, año 1927, Resolución dictada en el Pleno de la Suprema Corte de Justicia de la Nación, México, 10 de noviembre de 1927.

${ }^{43}$ AHSCJN, serie Queja, exp. 30, año 1928, El oficial mayor de la Secretaría de Agricultura y Fomento, México, a la Suprema Corte de Justicia de la Nación, 3 de febrero de 1928.

${ }^{44}$ AHSCJN, serie Queja, exp. 30, año 1928, Copia de expedientes relativos a los juicios de amparo núm. 319/927 y 292/27, México, 21 de febrero de 1928.

${ }^{45}$ AHSCJN, serie Queja, exp. 30, año 1928, El oficial mayor de la Secretaría de Agricultura y Fomento, México, a la Suprema Corte de Justicia de la Nación, 3 de febrero de 1928.

${ }^{46}$ AHSCJN, serie Conflicto Competencial, exp. 108, año 1928, Juan A. Coronado, México, al secretario de Acuerdos de la Suprema Corte de Justicia de la Nación, 25 de febrero de 1928.
}

EntreDiversidades. Revista de Ciencias Sociales y Humanidades, Vol. 9, Núm. 1 (18), enero-junio 2022. Páginas: 325-359 ISSN-e: 2007-7610. https://doi.org/10.31644/ED.V9.N1.2022.A14 
Roo, Filiberto Muñoz, tampoco quería aceptar el conocimiento del amparo, alegando que "en el D. F. comenzó a ejecutarse el acto que motivó el amparo y la aludida Secretaría de Agricultura y Fomento [era] la que ejecutaría ese acto al declarar caduco ese contrato". ${ }^{47}$ Finalmente, el presidente de la Suprema Corte resolvió, el 11 de abril, que se declaraba competente al juez de distrito en Quintana Roo con el fundamento de que la ejecución del acto reclamado había de realizarse en dicho Territorio. ${ }^{48}$ No se sabe qué hubo detrás de este cambio, si los jueces no quisieron involucrarse en esta querella entre Ramoneda y la Secretaría o hubo alguna presión política hacia ellos. Sea como fuere, el 23 de abril el Pleno de la Suprema Corte resolvió, por unanimidad de 8 votos, que se declaraba infundada la queja presentada por el subsecretario de Agricultura y Fomento, y el 31 de agosto, ya entrando en la siguiente temporada chiclera, el juez de distrito en Quintana Roo dictó sentencia amparando a Ramoneda. ${ }^{49}$

\section{La llegada del gobernador Siurob}

Mientras tanto, los jefes mayas seguían buscando manera de contrarrestar los daños que causaban las concesiones de Ramoneda. En enero de 1928, May envió una carta al Gral. Amado Aguirre, entonces gobernador del Distrito Sur de la Baja California, con quien tuvo buenas relaciones cuando este dirigía la comisión de estudios de Quintana Roo a principios de 1925. En la carta, que llegó más de un mes después al otro extremo de la República, le pedía que lo ayudara a someter unos asuntos con el presidente Calles y con el candidato presidencial, Álvaro Obregón, diciendo: "Si Ud. lo aprueba, yo iré a la ciudad de México provisto de sus consejos y de sus cartas-credenciales y creo que tanto Ud. como yo estaremos satisfechos de realizar una obra verdaderamente patriótica y nacional". ${ }^{50}$ Aunque la carta no decía nada en concreto sobre de qué se trataban los asuntos, Aguirre asumió, en una carta para el presidente Calles, que se refería a que se les diera "una porción de terreno en absoluta propiedad", bien acotada, para que no invadieran los terrenos donde explotaban chicle, y criticó la situación en la que los mayas tenían que pagar a Ramoneda y a sus socios, como Luis León, para trabajar. ${ }^{51}$

Aguirre contestó a May que no podía invitarlo a México y presentarlo personalmente al presidente, por no estar ahí, ${ }^{52}$ pero para ese entonces ya había llegado a Payo Obispo el nuevo gobernador, Gral. y Dr. José Siurob, oriundo de Querétaro, con quien May se entendió bien en un principio. Antes de viajar a Quintana Roo a tomar su puesto, Siurob revisó los expedientes

\footnotetext{
${ }^{47}$ AHSCJN, serie Conflicto Competencial, exp. 108, año 1928, Filiberto Muñoz, Payo Obispo, al secretario de Acuerdos de la Suprema Corte de Justicia de la Nación, 6 de marzo de 1928.

${ }^{48}$ AHSCJN, serie Conflicto Competencial, exp. 108, año 1928, Resolución dictada por el Presidente de la Suprema Corte de Justicia de la Nación, México, 11 de abril de 1928.

${ }^{49}$ AHSCJN, serie Queja, exp. 30, año 1928, Resolución dictada en el Pleno de la Suprema Corte de Justicia de la Nación, 23 de abril de 1928; serie Amparo en Revisión, exp. 3297, año 1927, Luis Arturo Romo, oficial mayor de la Secretaría de Agricultura y Fomento, México, a los magistrados de la Suprema Corte de Justicia de la Nación, 22 de septiembre de 1928.

${ }^{50}$ AHUNAM, AAA, caja IV, exp. 20, ff. 4-6, Francisco May, Santa Cruz de Bravo, a Amado Aguirre, 10 de enero de 1928.

${ }^{51}$ AGN, OC, exp. 121-A-M-37, Amado Aguirre, La Paz, a Plutarco Elías Calles, 22 de febrero de 1928.

${ }^{52}$ SBCHBT, AFM, núm. 19, Amado Aguirre, La Paz, a Francisco May, 18 de febrero de 1928.
}

EntreDiversidades. Revista de Ciencias Sociales y Humanidades, Vol. 9, Núm. 1 (18), enero-junio 2022. Páginas: 325-359 ISSN-e: 2007-7610. https://doi.org/10.31644/ED.V9.N1.2022.A14 
relativos al Territorio e hizo varias proposiciones a las secretarías correspondientes. Envío las copias al presidente Calles y le pidió instrucciones sobre algunos asuntos relevantes que le parecían de "especial importancia”. El primero fue el de las concesiones de Ramoneda. Quería conocer el criterio del presidente, porque sabía que los “compañeros León y Piña” protegían a los Ramoneda. ${ }^{53}$ También trató su propósito de darles terrenos fijos a los mayas y organizarlos en cooperativas, "para así sustraerlos al cacique [sic.], arraigarlos con la agricultura”. Acerca de este punto, en el memorándum para el secretario de Gobernación, escribió que habría que "proceder con mucho tino" y "tratarlos con absoluta buena fe y venciendo sus desconfianzas, sin alarmar demasiado al cacique para no provocar alguna inutil [sic. $]$ intemperancia o violencia de su parte" ${ }^{54}$

Así lo haría Siurob con los jefes mayas. Tan pronto como tomó la posesión del gobierno del Territorio el 14 de febrero, se enteró de que May, con Cámara Vales, exportaba chicle clandestinamente a Robert S. Turton, en Belice. Decomisaron un barco, el "San José”, propiedad de May, y descubrieron que los empleados de la Secretaría de Agricultura y Fomento, los de la Aduana y el jefe del destacamento federal en Vigía Chico estaban involucrados en el contrabando. ${ }^{55}$ Aunque acusaba repetidamente a estos funcionarios corruptos, Siurob trató bien a May. Valiéndose de algunos periodistas cubanos, que eran antiguos amigos de May, lo invitó a Payo Obispo a conferenciar. May aceptó, "no sin bastantes dificultades". ${ }^{56}$

La conferencia tuvo lugar en el palacio de gobierno en la tarde del 20 de marzo. Siurob pidió a May que se abstuviera de participar en el contrabando de chicle y le dijo que si él y su gente denunciaban a los contrabandistas ante el gobierno, les abonaría un 3\% sobre las participaciones que le tocaran por las cantidades de chicle, y los nombraría vigilantes y agentes especiales en todo el límite oeste del Territorio. May contestó que "había vendido su chicle sin tener conocimiento de los contrabandos" y que respecto al último caso en el que le fue decomisado el barco "San José", lo tenía arrendado a Cámara Vales, quien "hizo mal uso de él sin su consentimiento". Como May ofreció llevar su chicle personalmente a Cozumel y allí venderlo bajo la inspección de las autoridades, Siurob le prometió que haría gestiones para que se le devolviera el barco.

May, por su parte, le pidió ayuda con lo de la concesión de ferrocarril de Ramoneda. Le expuso que Ramoneda los explotaba haciéndoles pagar cantidades de dinero y que nunca había reparado la vía ferroviaria. En su informe al secretario de Gobernación, Siurob escribió que eso era cierto e incluso propuso que se cancelara la concesión —-solamente se había cancelado la de la Secretaría de Agricultura y Fomento- y se la diera o al gobierno del Territorio o al mismo May. Explicó que había "trazado una actitud de vigilancia y de espera respecto a la actitud de

\footnotetext{
${ }^{53}$ AGN, OC, exp. 427-Q-2, José Siurob, México, a Plutarco Elías Calles, 3 de enero de 1928.

${ }^{54}$ AGN, OC, exp. 427-Q-2, “Memorandum del C. Dr. José Siurob al Srio. de Gobernación sobre los datos obtenidos del Territorio de Quintana Roo y resolucion [sic.] de los problemas que presenta la administracion [sic.] de esa entidad federativa", s/f.

${ }^{55}$ AGN, OC, exp. 427-Q-2, José Siurob, Payo Obispo, a Fernando Torreblanca, 23 de febrero de 1928; SBCHBT, AFM, núm. 23, Francisco May, Cozumel, al capitán de puerto de Cozumel, 7 de mayo de 1928.

${ }^{56}$ AGN, DGG, exp. 2.310(32)5, José Siurob, Payo Obispo, a Adalberto Tejeda, 27 de marzo de 1928.
}

EntreDiversidades. Revista de Ciencias Sociales y Humanidades, Vol. 9, Núm. 1 (18), enero-junio 2022. Páginas: 325-359 ISSN-e: 2007-7610. https://doi.org/10.31644/ED.V9.N1.2022.A14 
los indios", pero se nota, por el tenor de su informe, que estaba contento del resultado de la conferencia y que pensaba que podría ganar la confianza de los jefes. ${ }^{57}$

Después de la conferencia, May le entregó a Siurob una carta dirigida al presidente Calles, donde expuso unos asuntos "halagadores" y otros "injustos o inicuos". Los halagadores eran "las frases de aliento, la esperanza y los afectos" que acababa de recibir del nuevo gobernador Siurob. La injusticia y las iniquidades se trataban nada menos que de Ramoneda. Se quejó de que Ramoneda le había cobrado 4000 pesos y que todavía lo amenazaba constantemente con que no lo permitiría trabajar si no aceptaba darle parte de sus ganancias. Siurob le prometió, según la carta, "el valiosísimo concurso de las facultades a él conferidas", pero, en cambio, el jefe de operaciones militares en Quintana Roo, Alfredo Martínez, le dijo que estaba obligado a defender y amparar a Ramoneda, porque así le había exigido la Secretaría de Guerra y Marina. ${ }^{58}$

Poco después de haber nombrado a Siurob gobernador de Quintana Roo y antes de que tomara posesión del puesto, el presidente Calles había girado órdenes para nombrarlo jefe de operaciones militares de Quintana Roo también, ${ }^{59}$ pero por alguna razón los trámites del cambio de ese puesto militar tardaron más de dos meses. El que firmó el primer acuerdo del nombramiento fue el subsecretario Piña, a quien se le acusaba ser uno de los protectores de Ramoneda. Decían que Martínez tomaba mucho y recibía dinero de quien fuera. ${ }^{60}$ Quizás Piña trató de que este continuara en el puesto y siguiera defendiendo a Ramoneda.

De cualquier modo, el cambio se hizo efectivo hasta finales de marzo. ${ }^{61}$ El punto es que así como Siurob estaba contento con el resultado de la conferencia, May también estaba contento con el nuevo gobernador y jefe de operaciones militares.

\section{La temporada chiclera de 1928-1929 Los vaivenes de las relaciones entre May y Siurob}

Aunque tanto May como Siurob salieron contentos de la conferencia en marzo, las relaciones entre ellos más tarde tendrían muchos vaivenes. Acercándose el inicio de la temporada chiclera de 1928-1929, May se quejó con Siurob de los contratistas Antonio Baduy y Celso Pérez Sandy. Siurob le explicó, a finales de mayo, que los terrenos concedidos a estos contratistas no afectaban los que se habían reservado para que se les dotaran a los mayas, y que tan pronto como llegara la orden para entregárselos, esos terrenos estarían definitivamente en su poder con título de la nación. ${ }^{62}$

${ }^{57}$ AGN, DGG, exp. 2.310(32)5, Acta de la conferencia entre José Siurob, Alfredo Martínez, Francisco May, et al., Payo Obispo, 20 de marzo de 1928; José Siurob, Payo Obispo, a Adalberto Tejeda, 27 de marzo de 1928.

${ }^{58}$ AGN, DGG, exp. 2.310(32)5, Francisco May, Payo Obispo, a Plutarco Elías Calles, 24 de marzo de 1928.

${ }^{59}$ AHSDN, 1-442, f. 168, Acuerdo firmado por el subsecretario de Guerra y Marina, Miguel Pińa, México, 11 de enero de 1928.

${ }^{60}$ AGN, OC, exp. 427-Q-2, José Siurob, Payo Obispo, a Fernando Torreblanca, 23 de febrero de 1928.

${ }^{61}$ AHSDN, 1-442, f. 181, Acuerdo firmado por el secretario de Guerra y Marina, Joaquín Amaro, México, 15 de marzo de 1928; AGN, DGG, exp. 2.310(32)5, José Siurob, Payo Obispo, a Adalberto Tejeda, 29 de marzo de 1928. ${ }^{62}$ SBCHBT, AFM, núm. 24, José Siurob, Payo Obispo, a Fancisco May, 30 de mayo de 1928.

EntreDiversidades. Revista de Ciencias Sociales y Humanidades, Vol. 9, Núm. 1 (18), enero-junio 2022. Páginas: 325-359 ISSN-e: 2007-7610. https://doi.org/10.31644/ED.V9.N1.2022.A14 
Ya para ese entonces, el optimismo que Siurob mostró hacia May en la conferencia de marzo se había desvanecido. A principios de junio Siurob envió al secretario de Gobernación un informe confidencial de 7 fojas sobre May, donde expuso: "el General May debe eliminarse como factor político y de resistencia empleando todos los medios legales que sean necesarios". May no había cumplido con los compromisos que firmó en la conferencia de marzo: por ejemplo, no ayudaba a los profesores para establecer escuelas, volvió a ejercer penas corporales a un foráneo y no había devuelto los objetos robados a otro contratista. El informe está lleno de acusaciones contra May, tanto que algunas se contradicen entre sí. Siurob hizo hincapié en que May era el único jefe maya que constituía una resistencia, que ya reinaba "un profundo descontento entre los propios elementos de May", y que, por ejemplo, Sóstenes Mendoza, el jefe de Chancah, ya era independiente de May y leal al gobierno. Pero a la vez escribió que en una junta que los mayas tuvieron con motivo de la fiesta del 3 de mayo — la fiesta de la Santa Cruz-, acordaron no permitir el establecimiento de las escuelas rurales, y que en Chancah tenían armas y no permitían llegar a ningún blanco. ${ }^{63}$

Mencionó también las concesiones de Ramoneda y escribió: "[S]obre ese particular sí creo que tienen razón los indios”. Argumentó que una buena parte de los terrenos habían estado explotados por ellos, y que el ferrocarril también era algo que principalmente ellos necesitaban para sacar los productos que explotaban. Pero eso sí, ya no propuso que se le concediera a May, sino al gobierno de Quintana Roo o a cualquiera de las Secretarías de Comunicaciones o de Guerra y Marina. ${ }^{64}$

En fin, Siurob pidió autorización para "obligar a May a dar garantías para el trabajo de todos", aprovechando, si era necesario, las órdenes de aprehensión en su contra, que ya existían y estaban suspensas, y para "desarmar a los indios que pudieran aparecer sospechosos después de una medida radical”. También pidió que se nombrara una comisión integrada por miembros de la Comisión Nacional Agraria y de la Secretaría de Agricultura y Fomento para estudiar las condiciones para entregarles tierras en posesión definitiva. Además, propuso, como una medida para dividir a los mayas, concederles por separado los permisos de explotación y no todos en nombre de May. ${ }^{65}$ Más de un mes después, el informe de Siurob llegó a manos del presidente Calle, quien autorizó lo pedido. ${ }^{66}$

Mientras tanto, Siurob disimulaba con May ese descontento o lo trataba "con absoluta buena fe”, como había planeado antes de llegar al Territorio. El mismo día en que escribió el informe confidencial sobre May, le escribió también a él, avisándole de que ya estaban listos los aparatos para reconstruir la línea telefónica entre Santa Cruz de Bravo y Vigía Chico y pidiéndole librar sus órdenes para que se hiciera el trabajo de reconstrucción. ${ }^{67}$ Unos días después, parece que May fue a Mérida y de ahí le mandó un telegrama a Siurob, pidiéndole ayuda para que se

\footnotetext{
${ }^{63}$ AGN, DGG, exp. 2.310(32)5, José Siurob, Payo Obispo, al secretario de Gobernación, 5 de junio de 1928..

${ }^{64}$ AGN, DGG, exp. 2.310(32)5, José Siurob, Payo Obispo, al secretario de Gobernación, 5 de junio de 1928..

${ }^{65}$ AGN, DGG, exp. 2.310(32)5, José Siurob, Payo Obispo, al secretario de Gobernación, 5 de junio de 1928.

${ }^{66}$ AGN, DGG, exp. 2.310(32)5, Jefe del Departamento Consultivo, Encargado de la Oficialía Mayor, Secretaría de Gobernación, México, a José Siurob, 21 de julio de 1928.

${ }^{67}$ SBCHBT, AFM, núm. 25, José Siurob, Payo Obispo, a Francisco May, 5 de junio de 1928.
}

EntreDiversidades. Revista de Ciencias Sociales y Humanidades, Vol. 9, Núm. 1 (18), enero-junio 2022. Páginas: 325-359 ISSN-e: 2007-7610. https://doi.org/10.31644/ED.V9.N1.2022.A14 
le devolviera el ferrocarril de Santa Cruz de Bravo a Vigía Chico. A esto le contestó Siurob que estaba en "absoluto acuerdo con su mensaje" y que ya se dirigía a México para que se le entregara bajo la inspección del gobierno. ${ }^{68}$

Para el siguiente mes de julio, las relaciones ya estaban mejor. El 24 de julio Siurob envió una carta al presidente Calles con motivo del asesinato del presidente electo Obregón. Escribió que había acompañado a May, en Payo Obispo, a recabar sus permisos de explotación, y que por eso "se logró un más amplio acercamiento con él". ${ }^{69}$ En el informe mensual de julio para la Secretaría de Gobernación, puso: "Respecto a los indios, seguidos en la mejor armonía, no ha habido necesidad de ejercer sobre ellos ninguna violencia, y no tengo temores de que lleguen a perturbar la páz $[s i c]. "{ }^{70}$ Por eso, a principios de agosto, cuando recibió la autorización del presidente de "tomar las medidas necesarias con May", contestó que ya no era necesario, porque la actitud de May había "variado completamente con relación al Gobierno". ${ }^{71}$

\section{La alianza entre May y Ramoneda}

No es nada sorprendente que el hecho de que Siurob ayudara a May a conseguir su permiso mejorara las relaciones entre los dos. Aunque a veces no respetaban las reglas e invadían terrenos de otros permisionarios, May y otros jefes mayas trataban de trabajar dentro del sistema legal de explotación forestal. Por eso, era importante conseguir los permisos del gobierno. Ya con los permisos podían empezar a prepararse para la nueva temporada chiclera.

Justo en julio, cuando fue a Payo Obispo a recabar sus permisos, May firmó un contrato de compra y venta de chicle para la temporada de 1928-1929 con Mac y Compañía, de Cozumel. Ya no pactó con Cámara Vales, pero el panorama del comercio no cambió mucho con respecto al de la temporada pasada, porque la Mac y Compañía compraba el chicle a Cámara Vales para venderlo a Turton, en Belice. La diferencia era que ahora el chicle de May llegaría a manos de Turton con un intermediario menos. Sin embargo, las condiciones para May no eran mejores que con Cámara Vales. Recibió de la compañía como anticipo 30000 pesos, en vez de 50 000, y se comprometió a entregarle todo el chicle a 70 pesos el quintal, en vez de $80 .^{72}$

Por eso, un mes después, May firmó otro contrato de compra y venta de chicle, pero ahora con el mismísimo Ramoneda. Según dice el contrato, los terrenos que le otorgó el gobierno no eran suficientes porque los que creyó que se encontraban dentro de su permiso estaban en posesión de Celso Pérez Sandy y otros permisionarios, y por eso deseaba trabajar en los mismos terrenos, pertenecientes a Ramoneda, en que había trabajado la temporada pasada. Acordaron que Ramoneda compraría toda la producción de May y de su gente, en Vigía Chico, a 75 pesos el quintal; May entregaría durante la temporada 5000 quintales como mínimo. Ramoneda

\footnotetext{
${ }^{68}$ SBCHBT, AFM, núm. 108, José Siurob, Payo Obispo, a Francisco May, 11 de junio de 1928.

${ }^{69}$ AGN, OC, exp. 427-Q-2, José Siurob, Payo Obispo, a Plutarco Elías Calles, 24 de julio de 1928.

${ }^{70}$ AGN, OC, exp. 427-Q-2, “Informe de julio de 1928”, José Siurob, Payo Obispo, al secretario de Gobernación, 31 de julio de 1928.

${ }^{71}$ AGN, DGG, exp. 2.310(32)5, José Siurob, Payo Obispo, al secretario de Gobernación, 9 de agosto de 1928.

${ }^{72}$ SBCHBT, AFM, núm. 26, Contrato celebrado entre Francisco May y Mac y Compañía, Payo Obispo, 19 de julio de 1928.
}

EntreDiversidades. Revista de Ciencias Sociales y Humanidades, Vol. 9, Núm. 1 (18), enero-junio 2022. Páginas: $325-359$ ISSN-e: 2007-7610. https://doi.org/10.31644/ED.V9.N1.2022.A14 
le facilitaría el libre tránsito por la vía ferroviaria y le entregaría 40000 pesos como anticipo tan pronto como la Mac y Compañía aceptara la devolución de los 30000 pesos que le había entregado a May. ${ }^{73}$

En la temporada pasada, May había conseguido de la Secretaría de Agricultura y Fomento permiso para explotar chicle en una buena parte de los terrenos concedidos en concesión a Ramoneda, y por eso solamente hizo un arreglo con este para poder utilizar el ferrocarril. Pero en esta temporada, ya que la Secretaría no le concedió el mismo terreno, optó por acercarse más a Ramoneda, de quien se había quejado tanto.

Una vez firmado el contrato, Ramoneda se convirtió en su socio preferido y May empezó a quejarse de otro permisionario, Antonio Baduy, y del gobernador Siurob. A principios de octubre, viajó a Mérida para enviar sus quejas, mediante diversos telegramas, al presidente Calles, al secretario de Agricultura y Fomento, Luis L. León, al secretario de Guerra y Marina, Joaquín Amaro, y a un diputado federal. ${ }^{74}$ En el telegrama dirigido al presidente, de 7 hojas, bastante largo para un telegrama, se quejó de que Siurob le había prometido, en Payo Obispo en marzo, que sus asuntos no sufrirían entorpecimiento alguno, pero que en poco tiempo las autoridades de Payo Obispo "se pusieron a ayudar pisoteando los derechos de [su] tribu a extranjeros". Explicó que la agencia general de la Secretaría de Agricultura y Fomento había otorgado permisos a varios extranjeros para explotar chicle en lugares cercanos a los terrenos de May y aún dentro de ellos, pero que en realidad estos extranjeros eran "prestanombres" de Antonio Baduy. Además, este se había quejado varias veces de May ante las autoridades en Payo Obispo, las cuales habían mandado varios emisarios y comunicaciones amenazándolo con el envío de fuerzas federales.

Con el secretario León se quejó de los agentes de la Secretaría y pidió que cancelara el permiso de Baduy. Enalteció a Ramoneda y criticó las compañías estadounidenses con una retórica nacionalista: "El hecho Señor Ingeniero de que yo esté celebrando en esta temporada todos mis negocios con mexicanos como el Señor Ramoneda de quién [sic.] mi tribu está agradecida por la ayuda financiera que nos ha prestado, me ha acarreado el odio de los extrangeros [sic.] que antes se han valido de nuestra ignorancia y poca experiencia para explotarnos".

Aunque May no lo mencionó, Baduy estaba asociado con otro jefe maya, Juan Bautista Vega, de Chumpón; ${ }^{75}$ de modo que el litigio se trataba también de la rivalidad entre los dos jefes mayas. Haber pactado con Ramoneda le daba cierta ventaja a May contra Vega. Un mes después de que May firmó el contrato con Ramoneda, Vega acudió a Payo Obispo, probablemente para pedir ayuda a las autoridades, y envió un telegrama al presidente Calles, pidiendo que se cancelara la concesión de Ramoneda y que se le diera permiso para trabajar en el mismo terreno. El presidente transcribió la petición al secretario de Agricultura y Fomento, quien contestó que ya había

\footnotetext{
${ }^{73}$ SBCHBT, AFM, núm. 28, Contrato celebrado entre Francisco May y Miguel A. Ramoneda, Santa Cruz de Bravo, 20 de agosto de 1928.

${ }^{74}$ AGN, OC, exp. 427-Q-2, Francisco May, Mérida, a Plutarco Elías Calles, 2 de octubre de 1928; SBCHBT, AFM, núm. 31-I, Francisco May, Mérida, a Luis L. León, 3 de octubre de 1928; núm. 31-II, Francisco May, Mérida, a Amado Fuentes B., s/f; AHSDN, XI/III/3-2456, tomo 1, ff. 22-23, Francisco May, Mérida, a Joaquín Amaro, 3 de octubre de 1928.
}

${ }^{75}$ AGN, OC, exp. 427-Q-2, José Siurob, México, a Plutarco Elías Calles, 8 de octubre de 1928.

EntreDiversidades. Revista de Ciencias Sociales y Humanidades, Vol. 9, Núm. 1 (18), enero-junio 2022. Páginas: $325-359$ ISSN-e: 2007-7610. https://doi.org/10.31644/ED.V9.N1.2022.A14 
acordado con el gobernador Siurob enviar ingenieros que deslindaran terrenos para concederlos en reservación a los mayas y que creía que en esa forma se resolverían las dificultades existentes. ${ }^{76}$

Quizá tenía razón: a largo plazo se resolverían los problemas de Vega de esa manera. Pero a corto plazo eso no le solucionaba nada. May, en cambio, consiguió lo que quería. Cuando fue a Mérida para enviar los telegramas a México, se reunió con Mac y Compañía y con Ramoneda. La compañía lo apoyó, enviando un telegrama al presidente Calles, suplicándole que dejaran trabajar libremente a los mayas, porque pagaban íntegros los derechos de explotación, "al igual o mejor que los permisionarios árabes", refiriéndose a Baduy. ${ }^{77}$ Ramoneda, por su parte, envió un telegrama al secretario León, supuesto autor intelectual de su proyecto en Quintana Roo. Utilizó la misma retórica nacionalista: suplicó la cancelación de los permisos de Baduy y otros permisionarios, que según eran los "tentáculos" de los que se valía "el millonario Turton de Belice" para arruinarles a May y a él. ${ }^{78}$

León había regresado al gabinete a encargarse, otra vez, de la Secretaría de Agricultura y Fomento a finales de julio, poco después del asesinato de Obregón (Dulles, 1961: 381). Las cosas iban mejor para May. A pesar de que el gobernador Siurob, que se encontraba en la capital, pidió al presidente que no hiciera caso a las peticiones de May y de sus socios, y a pesar de que Siurob y León acababan de acordar cómo ir dotando terrenos a los mayas, León escuchó las peticiones y giró instrucciones para la cancelación de los permisos de Baduy. ${ }^{79}$

Además, León ayudó a que se quedara la sentencia judicial que amparó a Ramoneda en contra del acuerdo presidencial que canceló su concesión. En septiembre, el oficial mayor de la Secretaría, según por orden del secretario, interpuso el recurso de revisión en contra de la sentencia dictada por el juez de distrito en Quintana Roo, con fecha 31 de agosto, que amparaba a Ramoneda. Pero a finales de noviembre el mismo secretario León escribió a los magistrados de la Suprema Corte de Justicia para pedirles que tuviera a la Secretaría por desistida de la revisión interpuesta, simplemente porque la Secretaría había "llegado a la conclusión de que la concesión otorgada al señor Miguel A. Ramoneda [debía] subsistir". ${ }^{0}$ Unos días después, dejó el cargo de secretario, porque el nuevo presidente interino, Emilio Portes Gil, lo substituyó por Marte R. Gómez (Dulles, 1961: 407).

\section{El envío del destacamento a Santa Cruz de Bravo}

Ante esta situación, Siurob tomó una medida drástica: en enero de 1929 envió un destacamento del ejército federal, compuesto de 20 soldados, a Santa Cruz de Bravo. May estaba ausente,

\footnotetext{
${ }^{76}$ AGN, OC, exp. 121-A-M-37, Juan Bautista Vega, Payo Obispo, a Plutarco Elías Calles, 20 de septiembre de 1928; Luis L. León, México, a Plutarco Elías Calles, 24 de septiembre de 1928.

${ }^{77}$ AGN, OC, exp. 427-Q-2, Mac y Compañía, Mérida, a Plutarco Elías Calles, 2 de octubre de 1928.

${ }^{78}$ SBCHBT, AFM, núm. 30, Miguel A. Ramoneda, Mérida, a Luis L. León, s/f.

${ }^{79}$ AGN, OC, exp. 427-Q-2, José Siurob, México, a Plutarco Elías Calles, 8 de octubre de 1928; Luis L. León, México, a Plutarco Elías Calles, 8 de octubre de 1928.

${ }^{80}$ AHSCJN, serie Amparo en Revisión, exp. 3297, año 1927, Luis Arturo Romo, México, a los magistrados de la Suprema Corte de Justicia de la Nación, 22 de septiembre de 1928; Luis L. León, México, a los magistrados de la Suprema Corte de Justicia de la Nación, 26 de noviembre de 1928.
}

EntreDiversidades. Revista de Ciencias Sociales y Humanidades, Vol. 9, Núm. 1 (18), enero-junio 2022. Páginas: $325-359$ ISSN-e: 2007-7610. https://doi.org/10.31644/ED.V9.N1.2022.A14 
atendiendo "sus negocios" en Valladolid. La llegada del destacamento ocasionó una tensión enorme en la capital maya. Cada vez llegaban más contingentes de mayas armados y se hacía más tensa la situación. Como si se reflejara el deseo de algunos, empezó a difundir el rumor de que May estaba sitiando Santa Cruz de Bravo, "con el fin de atacar al pueblo y acabar con los federales", y muchas familias se fugaron en plataformas de carga sobre la vía de ferrocarril rumbo a Vigía Chico (Ávila, 1993: 43-49).

Pero lo que hizo May fue diferente. En cuanto se enteró de lo ocurrido, en vez de regresar al pueblo, viajó a Mérida para enviar telegramas a México. Nombró a Ramoneda representante suyo para este asunto y le pidió que lo resolviera. ${ }^{81} \mathrm{Y}$ a la Secretaría de Guerra y Marina "ratificó" la queja contra Siurob que había enviado en octubre y solicitó que retirara el destacamento. ${ }^{82}$ Luego, cuando ya regresaba a Santa Cruz, recibió otra comisión que le informó de que su gente estaba abandonando el pueblo. Entonces, volvió a Mérida a enviar otros telegramas. Con el secretario de Guerra y Marina, admitió que el destacamento no lesionaba a nadie ni perjudicaba, pero solicitó que lo retirara para que su gente no se disgustara con él, ya que le achacaba toda la responsabilidad de lo que ocurría y le atribuía connivencia con las autoridades del Territorio. ${ }^{83}$ A Ramoneda le volvió a pedir que resolviera el problema, "entrevistando si necesario [al] C. Presidente por ser de urgente resolución”. ${ }^{84}$

Siurob llegó a Santa Cruz de Bravo antes que May. No había mujeres ni niños en la capital maya y en cambio vio "una gran población de chicleros mestizos de 950 personas que estaban esperando su liquidación al regreso de May”. También se encontraban 60 u 80 hombres armados, haciendo guardia de su santo. Al tercer día llegó May y junto con otros jefes mayas conferenció con el gobernador. ${ }^{85}$

Trataron más o menos los mismos temas que en la conferencia de marzo de 1928: el respeto a los concesionarios chicleros; el apoyo a las escuelas rurales; la abolición de la pena de azotes, etc. Pero también hubo algunos cambios importantes. Siurob les dijo que cada jefe maya podía obtener permisos para explotar chicle y así "trabajar independientemente, o con el General May, si así lo [preferían]". También se formó el Distrito de Santa Cruz de Bravo, gobernado por un delegado del gobierno, que estaría "ayudado" por un consejo formado por cinco personas mayas, pero ya no "vigilado" por May. ${ }^{86}$

May sabía lo que significaba todo esto; después de que trataron todos los asuntos, expresó su deseo de "retirarse con la gente que lo quisiera seguir" y dedicarse a sus negocios de chicle.

\footnotetext{
${ }^{81}$ SBCHBT, AFM, núm. 38, Francisco May, Mérida, a Miguel Ángel Ramoneda, 28 de enero de 1929; núm. 40, Francisco May, Mérida, a Miguel Ángel Ramoneda, 29 de enero de 1929.

${ }^{82}$ SBCHBT, AFM, núm. 39, Francisco May, Mérida, al Departamento de Estado Mayor de la Secretaría de Guerra y Marina, 29 de enero de 1929; núm. 41, Francisco May, Mérida, al Departamento de Estado Mayor de la Secretaría de Guerra y Marina, 29 de enero de 1929.

${ }^{83}$ SBCHBT, AFM, núm. 42, Francisco May, Mérida, al secretario de Guerra y Marina, 8 de febrero de 1929.

${ }^{84}$ SBCHBT, AFM, núm. 103, Francisco May, Mérida, a Miguel Ángel Ramoneda, 8 de febrero de 1929.

${ }^{85}$ AGN, EPG, exp. 478, José Siurob, Payo Obispo, al secretario de Gobernación, 23 de marzo de 1929.

${ }^{86}$ AGN, EPG, exp. 478, Copia del acta de la reunión entre José Siurob, Francisco May, et al., Santa Cruz de Bravo, s/f [febrero de 1929].
}

EntreDiversidades. Revista de Ciencias Sociales y Humanidades, Vol. 9, Núm. 1 (18), enero-junio 2022. Páginas: 325-359 ISSN-e: 2007-7610. https://doi.org/10.31644/ED.V9.N1.2022.A14 
Siurob, seguramente contento con lo que acababa de lograr, le contestó que "no deseaba que hubiera división entre las Tribus" y que creía que "la Tribu necesitaría de sus consejos siempre". La conferencia terminó con un abrazo que se dieron, a propuesta de Siurob, el jefe de la guardia federal y el de la maya. ${ }^{87}$ Siurob informó orgullosamente al gobierno federal: "esta es la primera véz $[s i c$.$] que entran fuerzas federales en esa región sin disparar un tíro [sic.], sin cometer el más$ leve desorden y sin provocar ninguna resistencia o protesta de los indios" ${ }^{88}$

\section{Las temporadas chicleras de 1929-1931 La rivalidad entre los jefes mayas}

Para ese entonces, algunos jefes mayas ya explotaban chicle independientemente de May, lo que Siurob quiso fomentar en la conferencia. Como era costumbre hacer con los permisionarios foráneos, a veces se rentaban terrenos entre ellos mismos. De hecho, May le pidió a Siurob su mediación en unas querellas suscitadas por esta situación. Por un lado, Juan Bautista Vega, de Chumpón, lo amenazaba, exigiéndole el chicle que habían explotado sus chicleros en los terrenos de May, pero que este les había quitado. Por otro lado, May tuvo problemas con Sóstenes Mendoza, de Chancah, también. Le había pagado una renta para explotar en los terrenos que habían concedido a Mendoza y a sus socios, Celso Pérez Sandy y Guadalupe Aguilar, pero la agencia de la Secretaría de Agricultura y Fomento le embargó a May 320 marquetas de chicle que explotó en los mismos terrenos, 12 mulas y algunos víveres y útiles, e incluso le puso una multa de 2000 pesos. ${ }^{89}$

Para comprar el chicle producido por los mayas, se necesitaba un permiso de la Secretaría de Agricultura y Fomento. Durante la temporada chiclera de 1927-1928, por ejemplo, la agencia general de la Secretaría en Payo Obispo expidió permiso a 14 contratistas para comprar a los mayas un total de 432000 kilogramos de chicle. ${ }^{90}$ Así mismo, la agencia dio autorización de explotar y exportar chicle a tres jefes mayas: Francisco May, 200000 kilogramos; Juan Bautista Vega, 100000 kilogramos; Sóstenes Mendoza, 20000 kilogramos. ${ }^{91}$ De ahí podemos suponer que más o menos 100000 kilogramos de chicle fueron producidos y vendidos por los mayas independientemente de estos tres jefes, es decir, individualmente o bajo el mando de otros jefes.

La estrategia de Siurob de otorgar a los jefes mayas permisos precarios por separado y así dividirlos funcionaba en cierto modo. En abril de 1929 Siurob acompañó a cada uno de los jefes que visitaron Payo Obipso para conseguir permiso en la agencia de la Secretaría. Aparte de

\footnotetext{
${ }^{87}$ AGN, EPG, exp. 478, Copia del acta de la reunión entre José Siurob, Francisco May, et al., Santa Cruz de Bravo, s/f [febrero de 1929].

${ }^{88}$ AGN, EPG, exp. 478, José Siurob, Payo Obispo, al secretario de Gobernación, 23 de marzo de 1929.

${ }^{89}$ AGN, EPG, exp. 478, José Siurob, Payo Obispo, al secretario de Gobernación, 10 de abril de 1929.

${ }^{90}$ AHSCJN, serie Amparo en Revisión, exp. 4040, año 1929, Alfonso González Gallardo, México, a Miguel Ángel Ramoneda, 16 de enero de 1929. De los 14 contratistas, el que tuvo la mayor cantidad fue Robert S. Turton, con 273000 kilogramos.

${ }^{91}$ AHSCJN, serie Amparo en Revisión, exp. 4040, año 1929, Alfonso González Gallardo, México, a Miguel Ángel Ramoneda, 22 de enero de 1929.
}

EntreDiversidades. Revista de Ciencias Sociales y Humanidades, Vol. 9, Núm. 1 (18), enero-junio 2022. Páginas: $325-359$ ISSN-e: 2007-7610. https://doi.org/10.31644/ED.V9.N1.2022.A14 
May, Vega y Juan de la Cruz Ce, de Icaiché, cuatro jefes más recibieron su ayuda. ${ }^{92}$ Incluso, en mayo, hubo un golpe de estado en contra del liderazgo de May. Dos jefes, Concepción Cituk y Evaristo Zuluub, formaron su cuartel con 70 u 80 hombres armados en un lugar denominado "Guardia”, unos 30 kilómetros al norte de Santa Cruz de Bravo. ${ }^{93}$ Parece que estaban de acuerdo con Vega y que querían matar a May, quien regresaba de Mérida. ${ }^{94}$ Aún así, no estaban en contra del gobierno; a los delegados del gobierno que los entrevistaron les explicaron que solamente querían sus tierras para explotar chicle, libres de las invasiones de los permisionarios foráneos. ${ }^{95}$

Durante esta temporada May recibió varias cartas de los jefes mayas en las que le pedían resolver sus problemas con los permisionarios. Un poco antes del golpe de estado, el mismo Zuluub y otros jefes de varios poblados al oeste de Santa Cruz le enviaron una carta en espańol. Le pidieron que pusiera alto a las invasiones que cometía el permisionario Antonio Baduy en sus terrenos, y le comentaron que los comerciantes que pasaban por la zona querían hacerles creer que May vendió sus tierras pero que ellos confiaban en él. ${ }^{96}$

A finales de junio, otros jefes, encabezados por Sóstenes Mendoza, de Chancah, le enviaron una carta en español, quejándose de los atropellos cometidos por los permisionarios Guadalupe Aguilar y Pascual Coral. El final de la carta dice, quizás aludiendo al golpe de estado: "Confian [sic.] los Jefes Mayas antes dichos que su General y Jefe atenderá la súplica que en nombre de todos sus subordinados le hacen y aprovechan esta circunstancia para exteriorizarle nuevamente su adhesión y apóyo [sic.]" ${ }^{97}$ En julio, May recibió tres cartas más de contenidos parecidos. La primera, preparada por los jefes de varios poblados al norte de Santa Cruz, menciona el rumor de que May había vendido sus terrenos, pero afirma la "indestructible lealtad" a él. ${ }^{98}$ La segunda, preparada por el mismo Cituk, entre otros, critica a Ramoneda, quien invadía sus terrenos. ${ }^{99}$ En la última, Concepción Poot, de Petcacab, se queja de que la agencia general de la Secretaría de Agricultura y Fomento los acusa de ser invasores de los terrenos del permisionario Pascual Coral y dice que están dispuestos a "expatriarse" al territorio inglés, donde "se puede disfrutar de las garantías a que tiene derecho toda comunidad que finca sus destinos en la honrada labor". ${ }^{100}$

El hecho de que las cartas estén en español quizá demuestra cierta distancia entre May y los otros jefes, quienes tuvieron que acudir con algunos foráneos — contratistas, comerciantes o profesores - para que sus voces fueran oídas por el "Jefe de las Tribus Mayas", como acostumbraba poner May en sus propias cartas. May no habría leído las cartas recibidas, sino que habría oído a

\footnotetext{
${ }^{92}$ AGN, EPG, exp. 478, José Siurob, Payo Obispo, al secretario de Gobernación, 1 de mayo de 1929.

${ }^{93}$ AGN, DGG, exp. 2.013.0(32)1, José Siurob, Payo Obispo, al secretario de Gobernación, 27 de mayo de 1929; EPG, exp. 478, G. Polanco G., Cozumel, a José Siurob, 28 de mayo de 1929.

${ }^{94}$ SBCHBT, AFM, núm. 59, José María Pech, Santa Cruz, a Francisco May, 11 de junio de 1929; núm. 60, José María Pech, Santa Cruz, a Francisco May, 12 de junio de 1929.

${ }^{95}$ AGN, DGG, exp. 2.013.0(32)1, José Siurob, Payo Obispo, al secretario de Gobernación, 27 de mayo de 1929.

${ }^{96}$ SBCHBT, AFM, núm. 46, Aquilino Balam, et al., Xpichil, a Francisco May, 26 de abril de 1929.

${ }^{97}$ SBCHBT, AFM, núm. 64, Sóstenes Mendoza, et al., Chancah, a Francisco May, 28 de junio de 1929.

${ }^{98}$ SBCHBT, AFM, núm. 65, Mauricio Cih, et al., Yaxché, a Francisco May, 4 de julio de 1929.

${ }^{99}$ SBCHBT, AFM, núm. 66, Eulalio Can, et al., Chanchén, a Francisco May, 8 de julio de 1929.

${ }^{100}$ SBCHBT, AFM, núm. 70, Concepción Poot, Petcacab, a Francisco May, 19 de julio de 1929.
}

EntreDiversidades. Revista de Ciencias Sociales y Humanidades, Vol. 9, Núm. 1 (18), enero-junio 2022. Páginas: 325-359 ISSN-e: 2007-7610. https://doi.org/10.31644/ED.V9.N1.2022.A14 
su secretario leerlas, en español, o tal vez traducidas en maya. Aún así, creo que las cartas son una muestra también de la esperanza que depositaban en él. Las cartas coinciden en solicitarle ayuda porque las peticiones que habían hecho ante las autoridades no cambiaban nada la situación. De hecho, incluso Juan Bautista Vega, quien se supone que rivalizaba con él, le pidió ayuda en el mismo mes de julio. May iba a viajar a Mérida y luego a México con la intención de ver al presidente de la República. Al saberlo, Vega envió a su secretario a Mérida a entrevistarlo y pedirle que gestionara ante el presidente para que cesaran los atropellos cometidos por Ramoneda y que les dieran terrenos para explotar chicle. ${ }^{101}$

\section{El viaje de May a México}

Después de la conferencia de febrero, las relaciones con el gobernador Siurob mejoraron. Este gestionaba con la Secretaría de Agricultura y Fomento para que no se le cobraran las multas y que se le devolviera las mulas decomisadas por la invasión de los terrenos concedidos a Pérez y a Aguilar. Insistía en que el agente de la Secretaría "fuera un poco más benévolo" con May, porque era "político", es decir, políticamente mejor, no presionarlo demasiado en esos momentos en que se le acababa de quitar el "cacicazgo" en Santa Cruz. También lo acompañó a la agencia de la Secretaría para que se le diera permiso precario para la temporada de 1929-1930. ${ }^{102}$ En el informe mensual de mayo puso que ahora con Santa Cruz en poder del gobierno, de ahí "radiaría" la civilización para los indios, cuyos principales jefes estaban todos "con el gobierno". ${ }^{103}$

Mientras mejoraban sus relaciones con Siurob, May se fue alejando de Ramoneda. A finales de mayo, cuando algunos jefes mayas planeaban el golpe de estado, viajó a Mérida y de ahí envió telegramas al presidente Portes Gil y al ex-presidente Calles. Les pidió que cancelaran las concesiones forestales que habían creado "una casta de aventureros extranjeros que sin piedad ni medida [talaba] y [destruía] los mejores bosques de la Nación y día a día [reducía] los medios de vida de las tribus mayas". Criticó, sobre todo, a Ramoneda, quien trataba de "asociarse a una compañía extranjera para activar más la explotación de los bosques de Quintana Roo" y de la vía ferroviaria de Santa Cruz de Bravo a Vigía Chico, que "donó la Revolución a las tribus mayas". ${ }^{104}$ Aunque en julio se contactó con el representante de Ramoneda para solicitar permiso de utilizar una parte de la vía para el corte de leña y otros trabajos, lo siguió criticando ante el gobierno. Tal vez hizo este viaje a Mérida porque las gestiones con Siurob no daban los resultados esperados. Aún así, parece que todavía no descartaba su ayuda, ya que, estando ahí, le envió un mensaje de que fue ahí a arreglar sus "asuntos de trabajo" y no para "pedir garantías" al gobernador de Yucatán. ${ }^{105}$

\footnotetext{
${ }^{101}$ SBCHBT, AFM, núm. 75, Amado Castillo, secretario y apoderado de Juan Bautista Vega, Mérida, a Francisco May, 25 de julio de 1929.

${ }^{102}$ AGN, EPG, exp. 478, José Siurob, Payo Obispo, a Marte R. Gómez, 16 de abril de 1929; José Siurob, Payo Obispo, al secretario de Gobernación, 1 de mayo de 1929.

${ }^{103}$ AGN, EPG, exp. 478, José Siurob, Payo Obispo, al secretario de Gobernación, 31 de mayo de 1929.

${ }^{104}$ SBCHBT, AFM, núm. 50, Francisco May, Mérida, a Emilio Portes Gil, 30 de mayo de 1929; Francisco May, Mérida, a Plutarco Elías Calles, 30 de mayo de 1929.

${ }^{105}$ SBCHBT, AFM, núm. 53, Francisco May, Mérida, a José Siurob, 4 de junio de 1929.
}

EntreDiversidades. Revista de Ciencias Sociales y Humanidades, Vol. 9, Núm. 1 (18), enero-junio 2022. Páginas: 325-359 ISSN-e: 2007-7610. https://doi.org/10.31644/ED.V9.N1.2022.A14 
A finales de julio, May volvió a viajar a Mérida, y de ahí prosiguió su viaje, ahora en avión, hasta México. Se entrevistó con los secretarios de Guerra y Marina y de Agricultura y Fomento y el mismo presidente de la República. Al secretario de Guerra y Marina, Joaquín Amaro, le pidió que celebrara con él un nuevo contrato de reconstrucción y explotación del ferrocarril como el contrato celebrado con Ramoneda. También le pidió que la Secretaría reconociera oficialmente el grado de "General, Jefe de las Tribus Mayas". Con el de Agricultura y Fomento, Marte R. Gómez, se quejó de su agencia en Quintana Roo, que favorecía a los permisionarios Antonio Baduy y Julio Martín, contratista que trabajaba desde hacía años en la región de Santa Cruz y que en esta temporada trabajaba para Ramoneda. ${ }^{106}$

Fue el momento oportuno: el 1 de agosto el presidente Portes Gil y el secretario Gómez cancelaron, una vez más, la concesión forestal otorgada a Ramoneda, y dos semanas después el secretario Amaro ordenó la cancelación de la concesión del ferrocarril. ${ }^{107}$ El viaje a México fue un éxito. Aunque no consiguió el contrato de ferrocarril, el secretario Gómez le comisionó "tramitar todo lo relativo a la explotación de chicle que [hacía] la tribu maya”, justo lo contrario de lo que promovía el gobernador Siurob. ${ }^{108}$ El respaldo que consiguió de los gobernantes del centro haría que su actitud con Siurob se volviera más audaz. Una vez más, May se había vuelto un problema para el gobernador.

\section{La dotación de la "reservación" de Chunyaxché}

Mientras tanto, Juan Bautista Vega buscaba resolver sus dificultades de otra manera. Como no tenía tantos nexos como May con los altos funcionarios del centro, optó por llevarse bien con el gobernador Siurob y aceptar sus programas de la reforma agraria.

Desde que asumió el cargo de gobernador en febrero de 1928, Siurob insistía repetidamente, ante el gobierno federal, en la necesidad de reconocerles a los mayas sus terrenos como ejidos. Argumentaba que dotándoles de ejidos y cancelando las grandes concesiones que abarcaban sus terrenos, no solamente cesarían las querellas entre ellos y los concesionarios, sino también se lograría minimizar las autoridades de "los caciques", es decir, los jefes mayas como May. A este se lo propuso en la conferencia de marzo de 1928, obviamente sin mencionar la intención de minimizar su "cacicazgo", y este le contestó que con gusto lo aceptaría después de consultar con otros jefes. Pero luego tardaron los trámites, principalmente por falta de apoyo del gobierno federal. La Comisión Nacional Agraria no mandaba ingenieros para medir terrenos, ni tampoco

\footnotetext{
${ }_{106}$ SBCHBT, AFM, núm. 79-I, Francisco May, México, a Joaquín Amaro, 7 de agosto de 1929; núm. 80, Francisco May, México, a Marte R. Gómez, 8 de agosto de 1929; núm. 81, Francisco May, México, a Emilio Portes Gil, 8 de agosto de 1929; AHSDN, XI/III/3-2456, tomo 1, f. 26, Francisco May, Santa Cruz de Bravo, a Joaquín Amaro, 21 de octubre de 1929.

${ }^{107}$ DOF, "Acuerdo por el cual se declara caduca la concesión otorgada al señor Miguel A. Ramoneda, para la explotación de una zona de bosques nacionales en el Territorio de Quintana Roo", 6 de agosto de 1929; "Acuerdo por el cual se cancela el contrato otorgado al señor Miguel A. Ramoneda, para la reconstrucción y explotación del Ferrocarril Militar de Quintana Roo", 20 de agosto de 1929.

${ }^{108}$ AGN, EPG, exp. 5/654, Marte R. Gómez, México, a Adolfo Roldán, 3 de septiembre de 1929.
}

EntreDiversidades. Revista de Ciencias Sociales y Humanidades, Vol. 9, Núm. 1 (18), enero-junio 2022. Páginas: $325-359$ ISSN-e: 2007-7610. https://doi.org/10.31644/ED.V9.N1.2022.A14 
lo apoyaban con sus proyectos los agentes de la Secretaría de Agricultura y Fomento, quienes, al criterio de Siurob, no eran "revolucionarios". 109

En la conferencia con los jefes mayas en febrero de 1929, les volvió a proponer su proyecto de dotación de terrenos. Vega no estaba presente, pero en abril solicitó terrenos para los mayas de Chumpón. En mayo llegó el tanto esperado ingeniero de la Comisión Nacional Agraria, ${ }^{110}$ quien trabajó, entre julio y septiembre, con la medición y otros trámites para la dotación de los terrenos. Por iniciativa del gobernador, la dotación se hizo en forma de "reservación" y no de ejido, porque la extensión permitida para la dotación de un ejido era mucho menor que la que los mayas necesitaban para la explotación chiclera. ${ }^{11}$ El 30 de septiembre se efectuó la entrega provisional de la Reservación de Chunyaxché, con una extensión de 40000 hectáreas, a los miembros de Chumpón y 15 poblados en sus alrededores.

La extensión otorgada se basó en un censo que preparó Vega, que se componía de 500 habitantes exactos. Aunque al ingeniero le parecía "un poco exagerado" y no podía rectificarlo por no saber el idioma y por el "hermetismo" que guardaban los mayas con él, tuvo que aceptarlo. Con el fundamento de que la calidad de los terrenos era "pobrísima" para una explotación agrícola y que la única forma de beneficiarlos era darles tierras en cantidades suficientes para explotar el chicle, se le asignó 80 hectáreas a cada individuo. Se suponía que cada terreno de 80 hectáreas se dividía en cinco partes para explotar una de ellas cada año y dejar que se renovara el monte. ${ }^{112}$

Mientras, fueron empeorando, una vez más, las relaciones entre Siurob y May, quien se volvió más audaz con él después del viaje a México. A mediados de octubre, May le envió una carta en donde le pedía que lo designara delegado del gobierno en Santa Cruz de Bravo. Le explicaba que después del viaje a México ya era "un hombre transformado" y que quería hacer justicia para su gente. Se quejaba de que un teniente del destacamento federal agredió a uno de los oficiales mayas, y que los militares insultaban a la gente, se embriagaban y hasta desplumaban a los trabajadores de la zona en una casa de juegos que se les permitía tener ahí. Terminó la carta con frases amenazadoras: "Solo espero su contestación para saber a qué debo atenerme, pues estoy pensando hacer un nuevo viaje a México, de no contestarme usted favorablemente concediéndome lo que pido". ${ }^{113}$ De hecho, el mismo día envió una carta al presidente Portes Gil, quejándose del destacamento y adjuntando la carta para Siurob. ${ }^{114}$

\footnotetext{
${ }^{109}$ AGN, OC, exp. 427-Q-2, Informe de José Siurob, Payo Obispo, 3 de marzo de 1928; José Siurob, Payo Obispo, a Plutarco Elías Calles, 8 de octubre de 1928; DGG, exp. 2.310(32)5, Acta de la conferencia entre José Siurob, Alfredo Martínez, Francisco May, et al., Payo Obispo, 20 de marzo de 1928; EPG, exp. 478, José Siurob, Payo Obispo, a Emilio Portes Gil, 15 de abril de 1929; José Siurob, Payo Obispo, a Marte R. Gómez, 16 de abril de 1929.

${ }^{110}$ AGN, DGG, exp. 2.013.0(32)1, José Siurob, Payo Obispo, al presidente de la Comisión Nacional Agraria, 25 de mayo de 1929.

${ }^{111}$ AGN, EPG, exp. 478, José Siurob, Payo Obispo, al secretario de Gobernación, 30 de septiembre de 1929.

${ }^{112}$ AGA, exp. 23/17167, legajo 1, ff. 36-38, César Zea, Payo Obispo, al presidente de la Comisión Local Agraria en el Territorio de Quintana Roo, 15 de octubre de 1929; f. 39, Informe de César Zea, Payo Obispo, 7 de octubre de 1929; f. 55, Acta de la entrega provisional de la Reservación de Chunyaxché, San Juan Bautista, 30 de septiembre de 1929 .

${ }^{113}$ AGN, DGG, exp. 2.384(32)3, Francisco May, Santa Cruz de Bravo, a José Siurob, 14 de octubre de 1929.

${ }^{114}$ AGN, DGG, exp. 2.384(32)3, Francisco May, Santa Cruz de Bravo, a Emilio Portes Gil, 14 de octubre de 1929.
}

EntreDiversidades. Revista de Ciencias Sociales y Humanidades, Vol. 9, Núm. 1 (18), enero-junio 2022. Páginas: $325-359$ ISSN-e: 2007-7610. https://doi.org/10.31644/ED.V9.N1.2022.A14 
Siurob le respondió con la misma astucia que May. Escuchó las quejas sobre los atropellos que cometieron algunos elementos del destacamento federal, los castigó, los retiró del destacamento, y ordenó suspender la venta de alcohol y cerrar la casa de juegos. Pero le negó condescendientemente la petición de nombrarlo delegado del gobierno, con el fundamento de que no quisiera darles la razón a los enemigos que decían que May seguía siendo un cacique y que él lo apoyaba. Luego puso: "debo de adverti[r]le que los Ingenieros de Fomento y otro funcionario que no quiero referirle, continúan acusándolo a usted y a mi ta $[\mathrm{m}]$ bien de que yo lo estoy protegiendo para que siga como cacique y lo pintan a usted como explotador de su propia raza". ${ }^{115}$ Sabemos que él mismo lo pintaba como tal, pero naturalmente proseguía su plan de "proceder con mucho tino". En diciembre escribió a la Secretaría de Gobernación que personalmente visitaría la zona maya a ver si podía persuadirlo a cambiar su actitud, y propuso, en caso de que no se lograra eso, llamarlo a la Ciudad de México con cualquier pretexto y retenerlo ahí para "educarlo" o castigarlo. ${ }^{116}$

\section{La temporada chiclera de 1930-1931 y después}

Para marzo de 1930, cuando se acercaba el inicio de la siguiente temporada chiclera, May ya no disimulaba su descontento con Siurob. Envió una comisión a Mérida, encargándole dos cartas, una a su nombre, dirigida al gobernador de Yucatán, Bartolomé García Correa, y otra a nombre de otros jefes mayas, dirigida al secretario de Guerra y Marina. En la que llevaba su nombre criticó abiertamente a Siurob, que según tenía "gran interes [sic.] en controlar esta zona para su bienestar personal". Solicitó ayuda para que se les dejara a los mayas la vía ferroviaria de Santa Cruz de Bravo a Vigía Chico. La otra carta pedía que se retirara el destacamento federal con el fundamento de que ya se aproximaba la fiesta dedicada a la Santa Cruz y la querían celebrar a solas. ${ }^{117}$

Siurob se ausentó del Territorio los primeros tres meses del año. Fue llamado a la capital para informarle de su gestión administrativa al presidente Portes Gil, que terminaba su interinato, y para asistir a la toma de posesión del presidente electo Pascual Ortiz Rubio. ${ }^{118}$ Cuando regresó a Quintana Roo, refutó los cargos que hicieron los jefes mayas contra el destacamento, y después emprendió la gira a la zona maya. ${ }^{119}$ En Santa Cruz de Bravo tuvo una conferencia con ellos y, según su informe, todos terminaron complacidos después de haber escuchado acerca de los proyectos de la dotación de tierras y la formación de cooperativas y después de "haber jurado la bandera en presencia de todo el pueblo de Santa Cruz". "Ante el felíz [sic.] éxito", escribió Siurob, se podía "dar como asegurada la paz en toda la Zona Maya". También puso que el único que engańaba a los mayas era "su antiguo cacique el General May", y que "dos pequeńos caciques",

\footnotetext{
${ }^{115}$ AGN, DGG, exp. 2.384(32)3, José Siurob, Payo Obispo, a Francisco May, 29 de octubre de 1929.

${ }^{116}$ AGN, EPG, exp. 478, José Siurob, Payo Obispo, al secretario de Gobernación, 3 de diciembre de 1929.

${ }^{117}$ AGN, DGG, exp. 2.013.0(32)1, Aquilino Balam, José Concepción Poot, et al., Santa Cruz de Bravo, a Joaquín Amaro, 6 de marzo de 1930; Francisco May, Santa Cruz de Bravo, a Bartolomé García Correa, s/f.

${ }^{118}$ AGN, DGG, exp. 2.310(32)10, Ricardo Suárez Escalante, Payo Obispo, al secretario de Gobernación, 1 de febrero de 1930.

${ }^{119}$ AGN, DGG, exp. 2.013.0(32)1, José Siurob, Payo Obispo, al secretario de Guerra y Marina, 8 de abril de 1930; José Siurob, Payo Obispo, al secretario de Gobernación, 22 de abril de 1930.
}

EntreDiversidades. Revista de Ciencias Sociales y Humanidades, Vol. 9, Núm. 1 (18), enero-junio 2022. Páginas: $325-359$ ISSN-e: 2007-7610. https://doi.org/10.31644/ED.V9.N1.2022.A14 
Evaristo Zuluub y Concepción Cituk, permanecían alejados a "la labor civilizadora del Gobierno" pero tenían "tan poca importancia”. ${ }^{120}$

Aunque parecía que Siurob avanzaba en su proyecto de asimilación de los mayas, la temporada chiclera de 1930-1931 le resultó pésima. Desde que llegó a Quintana Roo, Siurob había estado intentando cambiar el sistema de la explotación chiclera, organizando a los chicleros en cooperativas y fomentando cancelar grandes concesiones, para que las grandes compañías y los contratistas no siguieran llevándose la mayor parte de las ganancias. En contra de esta política cooperativista, las compañías estadounidenses boicotearon el chicle mexicano en esta temporada. Justo un día después de que Siurob informó orgullosamente al gobierno federal de la gira en la zona maya, el presidente de la Mexican Exploitation Company le avisó que la compañía no trabajaría en el Territorio en la temporada entrante, "a causa de los gastos, las dificultades puestas por las autoridades, la subida de los derechos la mala calidad de chicle y la oportunidad de comprar más barato en otros países". Su intención estaba clara: “[...] no queremos trabajar donde estamos considerados como explotadores del país y enemigos del gobierno". ${ }^{121}$ La William Wrigley Jr. Company también anunció reducir sus actividades. ${ }^{122}$ Luego, con la intervención del gobierno federal, que declaró que las explotaciones chicleras se llevarían a cabo exclusivamente por sociedades de régimen cooperativo, la situación empeoró, y las compañías aceptaron comprar el chicle solamente después del fin de la temporada y a cambio de la derogación del acuerdo presidencial. ${ }^{123}$

A mediados de febrero de 1931, en medio de la crisis de la industria chiclera, Siurob se fue del Territorio, substituido por Arturo Campillo Seyde. Según este, las cooperativas que había organizado aquél solo existían de nombre y estaban "totalmente desintegradas". ${ }^{124}$ Los logros en la asimilación de los mayas también parecían precarios. El nuevo gobernador alegó que los mayas estaban disgustados por "el engaño de que fueron víctimas" por parte de la administración anterior, que "pagó el chicle a menos de la mitad del valor que les habían ofrecido". Los maestros rurales que trabajaban entre los poblados mayas tenían que enfrentarse con la hostilidad de algunos elementos nativos, cuya actitud, "si bien no [era] de franca rebeldía con el Supremo Gobierno y con el Gobierno Local, sí [era] de independencia de las Tribus, que no [reconocían] más Autoridades que las de los mismos nativos". ${ }^{125}$ El sucesor de Siurob propuso desintegrar el Territorio de Quintana Roo con el fundamento de que el gobierno federal no podía solventar los gastos, lo que se hizo realidad en diciembre. ${ }^{126}$

\footnotetext{
${ }^{120}$ AGN, DGG, exp. 2.013.0(32)1, José Siurob, Payo Obispo, al secretario de Gobernación, 5 de junio de 1930.

${ }^{121}$ AGN, DGG, exp. 2.013.0(32)1, S. S. Yates, Cozumel, a José Siurob, 6 de junio de 1930.

${ }^{122}$ AGN, DGG, exp. 2.013.0(32)1, José Siurob, Payo Obispo, al secretario de Gobernación, 16 de junio de 1930.

${ }^{123}$ Para los detalles de la política cooperativista de Siurob y las reacciones de las compañías estadounidenses, véase Kawakami, 2017.

${ }^{124}$ AGN, POR, año 1931, exp. 106, Arturo Campillo Seyde, Payo Obispo, a Pascual Ortiz Rubio, 6 de marzo de 1931.

${ }^{125}$ AGN, POR, año 1931, exp. 106, Arturo Campillo Seyde, Payo Obispo, a Pascual Ortiz Rubio, 7 de junio de 1931.

${ }^{126}$ AGN, POR, año 1931, exp. 106, Memorándum de Ricardo Suárez Escalante, México, 2 de junio de 1931; DOF, "Decreto que modifica los artículos 43 y 45 de la Constitución General de la República, suprimiendo el Territorio de Quintana Roo", 19 de diciembre de 1931.
}

EntreDiversidades. Revista de Ciencias Sociales y Humanidades, Vol. 9, Núm. 1 (18), enero-junio 2022. Páginas: 325-359 ISSN-e: 2007-7610. https://doi.org/10.31644/ED.V9.N1.2022.A14 
Por otro lado, May fue expulsado del Territorio por Siurob poco antes de que este dejara la gubernatura, y tuvo que mudarse a Peto, Yucatán. ${ }^{127}$ Aún así, al contrario de lo que presumía Siurob, varios jefes mayas todavía lo apoyaban. En 1932, el inspector escolar de la zona maya del ex-Territorio informó que los mayas estaban divididos en dos grupos: uno, encabezado por Evaristo Zuluub, de Dzulá, que quería substituir a May, y otro, encabezado por Sóstenes Mendoza, de Chancah, que lo apoyaba. El grupo que se consideraba hostil contra el gobierno era el primero, pero en Chancah tampoco le fue bien al inspector. En un principio no lo dejaban entrar al pueblo, pero después, cuando uno de sus acompañantes inventó que eran "agentes chicleros de una Compañía Americana” y que iban a comprar chicle en dólares, se les acercaron, gritando alegremente “¡dólares, dólares!”. ${ }^{128}$

Por último, ¿qué pasó con Ramoneda? Como hemos visto, ganó un amparo contra el acuerdo presidencial de julio de 1927 que canceló la concesión forestal, pero el presidente Portes Gil volvió a declarar la cancelación el 1 de agosto de 1929. Entonces, promovió otra demanda de amparo contra el nuevo acuerdo presidencial, y el juez sexto supernumerario de distrito en el D.F., Ricardo Couto, le concedió el amparo el 26 de agosto. Sin embargo, la Secretaría de Agricultura y Fomento alegó que su agencia general en el Territorio había tomado posesión de los terrenos concedidos a Ramoneda un día antes de que se declarara la sentencia. Basándose en que los actos reclamados ya estaban "ejecutados", la Primera Sala de la Suprema Corte de Justicia de la Nación revocó la resolución del juez Couto, y le negó el amparo, el 14 de noviembre. ${ }^{129}$

En cuanto a la concesión del ferrocarril, que se canceló en el mismo mes de agosto de 1929, también promovió una demanda de amparo. La resolución final de la Segunda Sala de la Suprema Corte en este juicio fue concederle el amparo, pero solamente en el sentido de que la caducidad de la concesión fuera declarada administrativamente oyéndose previamente al concesionario y concediéndole, para su defensa, el término de 90 días. Después, en 1934, cuando el presidente Abelardo Rodríguez autorizó a la Secretaría de Agricultura y Fomento, que ahora se encargaba del ferrocarril, celebrar un contrato de arrendamiento del ferrocarril, Ramoneda presentó otra demanda de amparo, pero la Primera Sala de la Suprema Corte se lo negó en agosto de 1935, y la Segunda Sala de la misma confirmó el fallo y sobreseyó la causa en marzo de $1936 .{ }^{130}$

\footnotetext{
${ }^{127}$ AGN, POR, año 1931, exp. 106, Arturo Campillo Seyde, Payo Obispo, a Pascual Ortiz Rubio, 27 de abril de 1931; SBCHBT, AFM, núm. 100, José Juan Méndez, Mérida, a Rafael Martínez Cadena, 18 de mayo de 1932.

${ }^{128}$ UQROO, CEDOC, s/n [AHSEP, IV-100(04)(IV-4)(726.4)], Juan F. Flores, Santa Cruz de Bravo, al Jefe del Departamento de Escuelas Rurales, Secretaría de Educación Pública, 30 de abril de 1932; Juan F. Flores, Santa Cruz de Bravo, al Jefe del Departamento de Escuelas Rurales, Secretaría de Educación Pública, 31 de julio de 1932.

${ }^{129}$ AHSCJN, serie Amparo, exp. 2971, año 1929, Resolución dictada en la Primera Sala de la Suprema Corte de Justicia de la Nación, México, 14 de noviembre de 1929.

${ }^{130}$ AHSCJN, serie Amparo en Revisión, exp. 4040, año 1929, Resolución dictada en la Segunda Sala de la Suprema Corte de Justicia de la Nación, México, 31 de mayo de 1930; serie Amparo, exp. 3193, ańo 1934, Resolución dictada en la Primera Sala de la Suprema Corte de Justicia de la Nación, México, 31 de agosto de 1935; serie Amparo en Revisión, exp. 3193, año 1934, Resolución dictada en la Segunda Sala de la Suprema Corte de Justicia de la Nación, México, 10 de marzo de 1936. A pesar de que perdieron las concesiones de condiciones insólitas, los hermanos Ramoneda parecen haber seguido con el negocio del chicle y haber tenido cierto éxito, ya que en los informes oficiales de los años cuarenta aparece el nombre de José Ramoneda como agente de la William Wrigley Jr. Véase, AGN, MAC, exp. 705.2/281, Gabriel R. Guevara, Chetumal, a Manuel Ávila Camacho, 20 de febrero de 1942.
}

EntreDiversidades. Revista de Ciencias Sociales y Humanidades, Vol. 9, Núm. 1 (18), enero-junio 2022. Páginas: $325-359$ ISSN-e: 2007-7610. https://doi.org/10.31644/ED.V9.N1.2022.A14 


\section{Consideraciones finales}

En el presente artículo he analizado las relaciones entre los jefes mayas, el gobierno mexicano y los explotadores del chicle, principalmente Ramoneda. Las relaciones entre los jefes mayas y el gobierno se mantenían a base de intereses mutuos. Los jefes mayas querían el apoyo y el privilegio que les daba el gobierno para llevarles ventaja a otros jefes tanto en su mando en la región como en el negocio del chicle. El gobierno también necesitaba ayuda de algunos jefes sobresalientes para que controlaran su gente y aportaran a la incorporación de la región a la sociedad nacional, y para que se desarrollara la industria principal de la región. Por eso, los jefes mayas aceptaban algunos proyectos de incorporación, como la construcción de vías o la fundación de escuelas rurales, aunque quizá no con mucho afán. Los gobernantes de Quintana Roo y de México, por su parte, no restringían estrictamente sus actividades ilícitas, como el cobro de los "derechos" a los explotadores chicleros, los asaltos a los campamentos chicleros, o los castigos de azotazos. Eran relaciones con cierta tensión, que podían alterarse si el gobierno se metía demasiado en su administración, o en su negocio del chicle.

Las relaciones entre los jefes mayas y los explotadores del chicle se desarrollaban de igual modo. Generalmente, los explotadores trataban de llevarse bien con los jefes mayas y satisfacer sus exigencias, como el pago de los "derechos" de explotación. Si no se los pagaban o, aunque se los pagaran, si no se llevaban tan bien con ellos, sufrían asaltos a sus campamentos. Quejarse con el gobierno servía a veces, pero no siempre, ya que otras veces el gobierno prefería escuchar más a los jefes mayas. Ramoneda, que se valía de la influencia de algunos gobernantes del centro, también tuvo que jugar dentro de esta dinámica.

Obviamente, ninguna de las tres partes, es decir, los mayas, el Estado mexicano y el capital chiclero, era homogénea. Siempre existía una rivalidad entre los jefes mayas. Negociaban derechos de explotación entre ellos mismos, como en el caso de May y Mendoza. Cada jefe se asociaba con distintos explotadores foráneos y competían entre ellos, como en el caso de May y Vega. Así mismo, cada gobernador de Quintana Roo trataba diferente a los mayas, y a veces el presidente de la República o los secretarios del gobierno federal contradecían las políticas del gobernador. Los explotadores también estaban en una constante lucha entre sí por conseguir buenos tratos con el gobierno y con los mayas.

Los jefes mayas, sobre todo May, entendían bien esta dinámica. Para resolver los problemas como la presencia del destacamento en Santa Cruz o las invasiones a sus terrenos por los permisionarios foráneos, May no acudió a las armas como hacían sus antecesores durante la Guerra de Castas. Había jefes que querían que May fuera más beligerante contra el gobierno mexicano, pero sus armas, en cambio, eran el chicle y las conexiones con los altos funcionarios del gobierno. Por ser considerado el jefe más influyente y representante de los mayas de Quintana Roo, May tenía la ventaja de tener nexos con varias figuras importantes de la política y la economía de ambos niveles, local y nacional: gobernadores de Quintana Roo y de Yucatán; presidentes de la República; secretarios del gobierno federal; capitalistas nacionales y extranjeros, etc. A menudo, viajaba a Payo Obispo, Cozumel, Valladolid, Mérida, e incluso a México, para enviarles telegramas o entrevistarse personalmente con ellos. Para que se oyeran sus quejas y se resolvieran sus problemas, podía escoger de entre varios canales que tenía. Cuando se llevaba bien

EntreDiversidades. Revista de Ciencias Sociales y Humanidades, Vol. 9, Núm. 1 (18), enero-junio 2022. Páginas: 325-359 ISSN-e: 2007-7610. https://doi.org/10.31644/ED.V9.N1.2022.A14 
con el gobernador de Quintana Roo, este era el destinatario más frecuente de sus peticiones. Pero cuando no se llevaba bien con él, se dirigía a otros, por ejemplo, al jefe de operaciones militares en Quintana Roo o al gobernador de Yucatán, para que estos llevaran las peticiones al gobierno federal, o también se dirigía directamente a los altos funcionarios del gobierno federal como el presidente y los secretarios.

Como hemos visto, Concepción Cituk y Evaristo Zuluub se separaron de May y fundaron un nuevo centro religioso en Guardia en 1929. Luego, en los años treinta, contactaron con los estadounidenses que realizaban investigaciones arqueológicas en Chichén Itzá y les pidieron ayuda para seguir la lucha armada contra los mexicanos (Sullivan, 1989). No es sorprendente que estos mayas, llamados "separados", hayan sido considerados verdaderos "herederos" de los protagonistas de la Guerra de Castas (Villa, 1945: 28-35; Bartolomé y Barabas, 1977: 42-79; Careaga, 1998: 137-141) y que la historiografía existente haya prestado menos atención a la época de May que a la rebelión decimonónica y a los "separados".

Sin embargo, detrás de esta tendencia uno puede hallar una visión simplista que limita la definición de resistencia a la lucha armada. Y el caso de Ramoneda que analizamos en este artículo nos demuestra que, lejos de dejar de resistir, los jefes mayas como May y Vega buscaron y forjaron una nueva estrategia de resistencia para la época en que ya no era factible seguir la lucha armada. En fin, los "separados" de los años treinta adoptaron la misma estrategia de resistencia que forjaron sus antecesores en los veinte: el chicle y la diplomacia. En este sentido, podemos concluir que los jefes mayas de la década de 1920, que mediaban entre las aldeas mayas y el mundo exterior, lo hicieron también entre dos épocas: la de la Guerra de Castas, cuando lucharon con armas, y la actualidad, donde luchan sin armas.

\section{Biografía citada}

Aguirre, Amado (1925). Informe que rinde al C. presidente de la República el jefe de la comisión nombrada por el mismo, para hacer el estudio del Territorio Federal de Quintana Roo integrada por el C. general Amado Aguirre, capitán de fragata Alberto Zenteno, ingeniero civil Salvador Toscano, C. Juan de Dios Rodríguez, ingeniero agrónomo Rafael López Ocampo

y CC. Gregorio M. Avalos y J. Guillermo Freymann. Estudio practicado de enero a abril de 1925. México, D. F., México: Imprenta de la Dirección de Estudios Geográficos y Climatológicos.

Alcorn, Peter W. (2002). "Chicle (Manilkara zapota)”, en Shanley, Patricia, et al. (eds.). Tapping the Green Market: Certification and Management of Non-Timber Forest Products. London y Stirling, United Kingdom: Earthscan, pp. 49-60.

Ávila Zapata, Felipe Nery (1993). El General May: último Jefe de las Tribus Mayas. México, D. F., México: Gobierno del Estado de Quintana Roo, Fondo de Publicaciones y Ediciones. Bartolomé, Miguel Alberto y Barabas, Alicia Mabel (1977). La resistencia maya: relaciones interétnicas en el oriente de la peninsula de Yucatán. México, D. F., México: Instituto Nacional de Antropología e Historia.

EntreDiversidades. Revista de Ciencias Sociales y Humanidades, Vol. 9, Núm. 1 (18), enero-junio 2022. Páginas: 325-359 ISSN-e: 2007-7610. https://doi.org/10.31644/ED.V9.N1.2022.A14 
Beteta, Ramón (1937). Tierra del chicle. México: s/e.

Careaga Viliesid, Lorena (1998). Hierofanía combatiente: Lucha, simbolismo y religiosidad en la Guerra de Castas. México, D. F., México: Universidad de Quintana Roo, Consejo Nacional de Ciencia y Tecnología.

Dulles, John W. F. (1961). Yesterday in Mexico: A Chronicle of the Revolution, 1919-1936. Austin, Texas, United States of America: University of Texas Press.

Dumond, Don E. (1997). The Machete and the Cross: Campesino Rebellion in Yucatan. Lincoln, Nebraska, United States of America: University of Nebraska Press.

Dutt, Rajeshwari (2017). Maya Caciques in Early National Yucatán. Norman, Oklahoma, United States of America: University of Oklahoma Press.

González Navarro, Moisés (1970). Raza y tierra: La guerra de castas y el henequén. México, D. F., México: El Colegio de México.

Hostettler, Ueli (1996). Milpa Agriculture and Economic Diversification: Socioeconomic Change in a Maya Peasant Society of Central Quintana Roo, 1900-1990s, Tesis para obtener el grado de Doctorado, Institut für Ethnologie, University of Berne.

Kawakami, Ei (2013). "Intermediario entre dos mundos: Francisco May y la mexicanización de los mayas rebeldes". Historia Mexicana, 62 (3), pp. 1153-1210. También disponible en: https://historiamexicana.colmex.mx/index.php/RHM/article/view/103

Kawakami, Ei (2017). "El cooperativismo y la industria chiclera en la época posrevolucionaria". Mexican Studies/Estudios Mexicanos, 33 (1), pp. 32-65. También disponible en: https:// doi.org/10.1525/mex.2017.33.1.32

Konrad, Herman W. (1987). "Capitalismo y trabajo en los bosques de las tierras bajas tropicales mexicanas: el caso de la industria del chicle”. Historia Mexicana, 36 (3), pp. 465-505. También disponible en: https://historiamexicana.colmex.mx/index.php/RHM/article/ view/1978

Konrad, Herman W. (1991). "Capitalism on the Tropical-Forest Frontier: Quintana Roo, 1880s to 1930”, en Brannon, Jeffery T., y Joseph, Gilbert M. (eds.). Land, Labor, and Capital in Modern Yucatán: Essays in Regional History and Political Economy. Tuscaloosa, Alabama, United States of America: The University of Alabama Press, pp. 143-171.

Lapointe, Marie (1983). Los mayas rebeldes de Yucatán. Zamora, Michoacán, México: El Colegio de Michoacán.

Mathews, Jennifer P. (2009). Chicle: The Chewing Gum of the Americas, from the Ancient Maya to William Wrigley. Tucson, Arizona, United States of America: The University of Arizona Press.

Ponce Jiménez, Martha Patricia (1990). La montaña chiclera campeche: vida cotidiana y trabajo (1900-1950). México, D. F., México: Centro de Investigaciones y Estudios Superiores en Antropología Social, Cuadernos de la Casa Chata.

Ramayo Lanz, Teresa (2014). Política, economía chiclera y territorio: Quintana Roo 1917-1940. Mérida, Yucatán, México: Ediciones de la Universidad Autónoma de Yucatán. 
Ramos Díaz, Martín (1999). "La bonanza del chicle en la frontera caribe de México. Indígenas y empresarios, 1918-1930". Revista mexicana del caribe, Año 4, Núm. 7, pp. 172-193. También disponible en: http://recaribe.uqroo.mx/numeros/anteriores/07/07ramos.pdf

Ramos Díaz, Martín (2001). Niños mayas, maestros criollos. Rebelión indígena y educación en los confines del trópico. México, D. F., México: Universidad de Quintana Roo, Fundación Oasis, Gobierno del Estado de Quintana Roo.

Redclift, Michael (2004). Chewing Gum: The Fortune of Taste. New York, United States of America, London, United Kingdom: Routledge.

Reed, Nelson (1964). The Caste War of Yucatán. Stanford, California, United States of America: Stanford University Press.

Rugeley, Terry (1996). Yucatán's Maya Peasantry and the Origins of the Caste War. Austin, Texas, United States of America: University of Texas Press.

Rugeley, Terry (2009). Rebellion Now and Forever: Mayas, Hispanics, and Caste War Violence in Yucatán, 1800-1880. Stanford, California, United States of America: Stanford University Press.

Schwartz, Norman B. (1990). Forest Society: A Social History of Peten, Guatemala. Philadelphia, Pennsylvania, United States of America: University of Pennsylvania Press.

Sullivan, Paul (1989). Unfinished Conversations: Mayas and Foreigners between Two Wars. New York, United States of America: Alfred A. Knopf.

Sullivan, Paul (1998). ¿Para qué lucharon los mayas rebeldes? Vida y muerte de Bernardino Cen. México, D. F., México: Universidad de Quintana Roo.

Sullivan, Paul (2004). Xuxub Must Die: The Lost Histories of a Murder on the Yucatan. Pittsburgh, Pennsylvania, United States of America: University of Pittsburgh Press.

Vadillo López, Claudio (2001). Los chicleros en la región de Laguna de Términos, Campeche: 18901947. Ciudad del Carmen, Campeche, México: Universidad Autónoma del Carmen.

Villa Rojas, Alfonso (1945). The Maya of East Central Quintana Roo. Washington, D. C., United State of America: Carnegie Institution of Washington.

Villalobos González, Martha Herminia (2004). "Del antiguo al nuevo régimen. Bosque y territorialidad entre los mayas de Quintana Roo, 1890-1935”, en Macías Zapata, Gabriel Aarón (coord.). El vacio imaginario: Geopolitica de la ocupación territorial en el Caribe oriental mexicano. México, D. F., México: Centro de Investigaciones y Estudios Superiores en Antropología Social, pp. 199-230.

Villalobos González, Martha Herminia (2006). El bosque sitiado: Asaltos armados, concesiones forestales y estrategias de resistencia durante la Guerra de Castas. México, D. F., México: Instituto Nacional de Antropología e Historia, Centro de Investigaciones y Estudios Superiores en Antropología Social, Consejo Nacional para la Cultura y las Artes, Miguel Ángel Porrúa. 